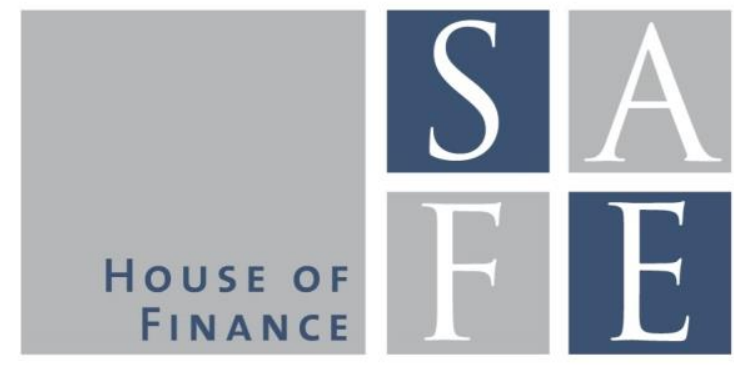

WORKING PAPER SERIES

Benjamin Clapham - Peter Gomber - Martin Haferkorn - Paul Jentsch Sven Panz

\title{
Circuit Breakers - A Survey among International Trading Venues
}

SAFE Working Paper No. 197

SAFE I Sustainable Architecture for Finance in Europe

A cooperation of the Center for Financial Studies and Goethe University Frankfurt 


\title{
Circuit Breakers -
}

\section{A Survey among International Trading Venues}

\author{
Peter Gomber, Benjamin Clapham, \\ Martin Haferkorn, Sven Panz, Paul Jentsch \\ Chair of e-Finance \\ Faculty of Economics and Business Administration \\ Goethe University Frankfurt
}




\section{Table of Contents}

1 Executive Summary ........................................................................................................................ 1

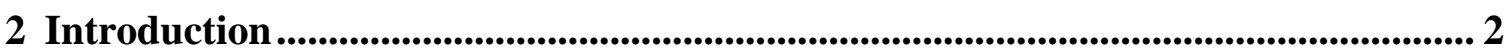

2.1 Categories of Circuit Breakers ....................................................................... 2

2.2 Overview and Background of the Survey ...................................................... 4

3 Participation Concerning Markets and Asset Classes.............................................5 5

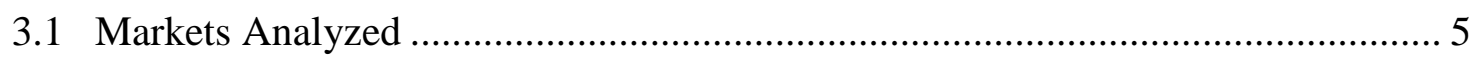

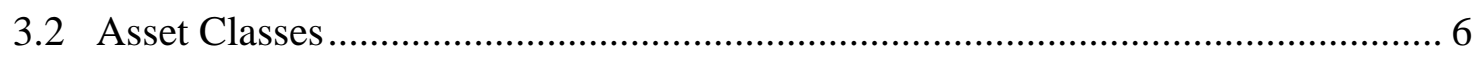

4 Types of Circuit Breaker Implementations ............................................................. 7

4.1 Implementation of Circuit Breakers by Market Type and Region ......................... 7

4.2 Types of Circuit Breakers Implemented at Cash and Derivatives Markets ............ 9

5 Triggering Processes of Circuit Breakers ........................................................................ 14

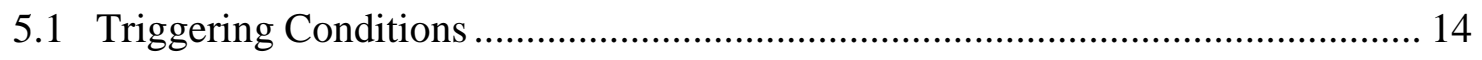

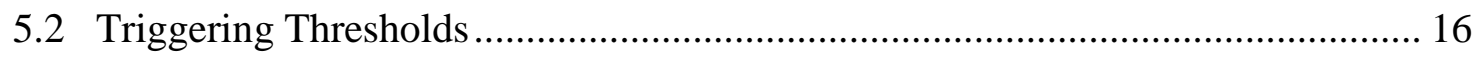

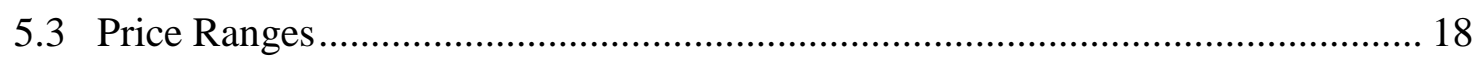

5.4 Parametrization and Duration of Circuit Breakers .......................................... 19

6 Information Provision on and during Circuit Breakers......................................... 24

7 Initiation and Revision of Circuit Breaker Mechanisms.......................................... 26

8 Coordination of Circuit Breakers................................................................................ 28

9 Summary and Key Takeaways .................................................................................. 32

10 References ..................................................................................................................................... 35

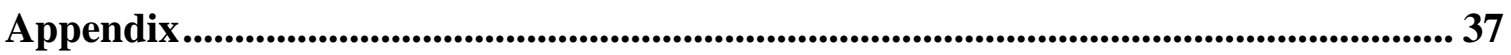

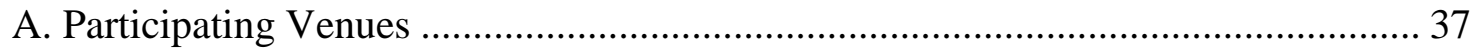

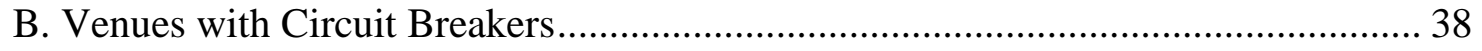

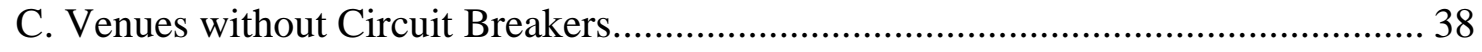

D. Participating Venues in the 2008 and 2016 WFE Surveys on Circuit Breakers ...... 39

E. Market Models of the Survey Participants ................................................................. 40

F. Historical Development of Circuit Breaker Implementations by Region ................. 41 


\section{Executive Summary}

Circuit Breakers are widely implemented in 2016. Currently, the majority (86\%) of the responding trading venues use circuit breakers to ensure investor protection and to increase market integrity and stability. Compared to the previous study (WFE, 2008), the proportion of exchanges using circuit breakers increased from $60 \%$ to $86 \%$.

The most widely-used circuit breaker mechanisms are market-wide trading halts and volatility interruptions. On cash markets, market-wide trading halts and volatility interruptions represent $72 \%$ of the implementations. On derivatives markets, most exchanges coordinate their circuit breaker with their cash market (40\%) followed by market-wide trading halts (20\%) and volatility interruptions (13\%).

The majority of mechanisms do not differentiate between upward or downward market movements. Either way, when price fluctuations are extensive, circuit breakers are triggered. In the cash market segment, only 15 of 47 (32\%) mechanisms react solely to downward market movements. Thirteen of $15(87 \%)$ circuit breakers on the derivatives markets are triggered in both directions. Only in two cases of internal coordination between cash and derivatives markets, the respective trading halt on both market segments is only triggered in the event of downward market movements.

Most circuit breakers are triggered by predetermined price ranges that are either static or dynamic with the former being set wider than the latter. It is noticeable that only volatility interruption mechanisms apply dynamic price ranges (in most cases in combination with static ranges). The other three types of circuit breakers rely on static price ranges, which typically refer to the previous day's closing prices or last auction prices.

Transparency dominates when it comes to providing information on the thresholds to market participants. The vast majority (92\%) of responding exchanges publishes all information regarding the threshold determination process and the thresholds themselves. However, three exchanges only provide general information, but do not disclose specific parameters such as the width of price ranges to avoid deliberate triggering of the circuit breaker.

There is support for greater coordination of circuit breakers across venues. The study gathered a multitude of opinions of global trading venues and thus serves as further input to this important topic. Although 20 of 29 responding exchanges (69\%) generally favor the concept of coordination, only $32 \%$ of the exchanges that make use of circuit breakers already coordinate them with other venues. 


\section{Introduction}

Circuit breakers ${ }^{1}$ are important mechanisms to prevent excess short-term volatility and to assure price continuity. They were first implemented at NYSE in response to Black Monday in 1987 and are well-established in today's financial markets. In the last years, exchanges invested in circuit breaker implementations to protect their market participants against excessive price movements. Numerous market events highlight the importance of circuit breakers in today's financial markets. Most referenced in this respect is the May 6 ${ }^{\text {th }}, 2010$ Flash Crash where the Dow Jones dropped by $9 \%$ within ten minutes and quickly rebounded. Also, immense fluctuations of equity prices in August 2015, macroeconomic events such as the abolishment of the Swiss Franc-Euro peg in January 2015 and the Brexit referendum in June 2016 caused significant market activity. During times of high volatility, circuit breakers enable market participants to reassess information and re-evaluate their trading strategies, positions and orders which increases market stability (Madhavan, 1992; Ma et al., 1989). However, circuit breakers are controversial within the scientific community. For example, Lauterbach and Ben-Zion (1993) argue that investors are unable to trade und cannot manage their inventories during a circuit breaker. Fama (1989) note that circuit breakers postpone price discovery and harm efficiency and Subrahmanyam (1994) found that circuit breakers exacerbate price changes on other markets and in following periods. The conclusions of recent empirical studies on the effects of circuit breakers on market quality are mixed. While several empirical studies observe an increase in volatility after circuit breakers as well as a volatility spillover across financial instruments (Corwin and Lipson, 2000; Christie et al., 2002; Brugler and Linton, 2016), other research finds that volatility decreases and reverts to normal levels after the activation of a circuit breaker (Kim et al., 2008; Abad and Pascual, 2010; Gomber et al., 2013).

\subsection{Categories of Circuit Breakers}

In general, three different categories of circuit breaker mechanisms can be observed (Moser, 1990) and each of them aims to secure market stability. Order-imbalance circuit breakers aim to protect the interests of market makers in specialist markets. Volume-induced circuit breakers are directed at protecting against an overload of back-office operations. Finally, price-change circuit breakers are implemented to protect securities from excessive volatility and unintended

\footnotetext{
${ }^{1}$ In the following, the term "Circuit Breaker" refers to all safeguards aimed at promoting market stability incl. trading halts, volatility interruptions, limit up limit down mechanisms, order rejections, etc.
} 
price changes. In this survey, we focus on the latter and investigate different aspects within this report. According to the Brady Commission's definition², circuit breaker mechanisms include price limits, position limits, volume limits, trading halts reflecting order imbalances, and trading halts in derivatives associated with conditions in the primary marketplaces (Brady, 1988). For this survey, we use the definition of Abad and Pascual (2013) who categorize trading halts and price limits as the two main types of circuit breakers. Trading halts occur when a trading venue stops trading on a specific security for a certain time period. During a trading halt, no trades are executed and no new prices are determined. These trading halts can be broken down into market-wide trading halts affecting all financial instruments in a market and security-specific trading halts that only halt trading in a single security. Price limits allow trades to occur only in predefined price ranges thereby preventing large price jumps. Orders that would result in a trade outside these price ranges are rejected (order rejection) or cause a switch from continuous trading to a call auction or extend an existing call auction (volatility interruptions). In this survey, we analyze the implementation of the following types of circuit breakers on exchanges worldwide: order rejections, volatility interruptions, market-wide trading halts and single-instrument trading halts (Figure 1).

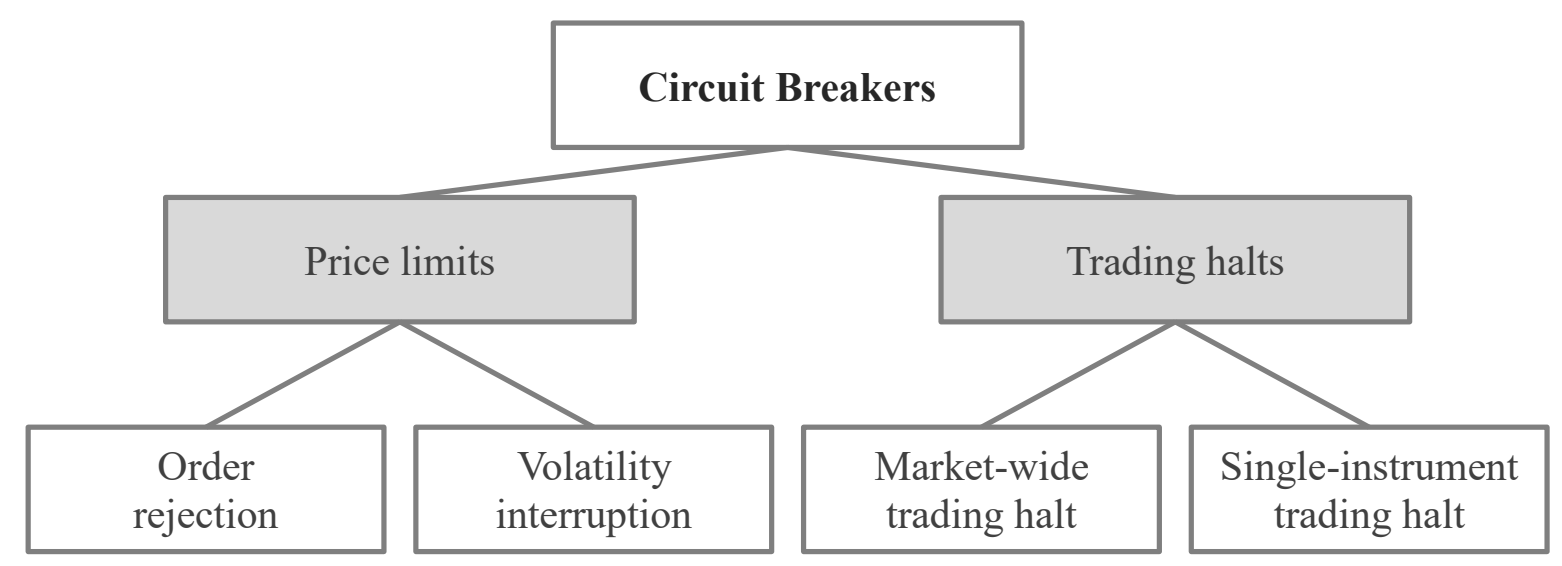

Figure 1: Classification of circuit breakers (illustration based on Abad and Pascual, 2013).

Theoretically, the activation of circuit breakers can be initiated automatically (rule-based) or at the discretion of the exchange official or regulator (Abad \& Pascual, 2013). Rule-based mechanisms can be triggered either by single-instrument price movements or by index movements that exceed certain thresholds. Consequently, an activated safeguard mechanism can affect the whole market or a single-instrument.

\footnotetext{
${ }^{2}$ Following the stock market crash in 1987, the US government mandated the Task Force on Market Mechanisms, known as the Brady Commission, to investigate the causes of the crash.
} 


\subsection{Overview and Background of the Survey}

To shed light on the actual implementations of circuit breakers, an international survey on circuit breakers was conducted by the World Federation of Exchanges (WFE) and the Chair of eFinance, Goethe University Frankfurt ${ }^{3}$. This report presents the results of the survey on circuit breaker mechanisms among 63 WFE member trading venues ${ }^{4}$ and nine additional non-members of the WFE (two exchanges and seven MTFs). In total, $44^{5}$ trading venues answered the questionnaire, resulting in a response rate of $61 \%$.

The survey was conducted in the following stages: First, a pre-test was conducted with four exchanges from different continents followed by conference calls with the pre-test participants, the Chair of e-Finance and the WFE. The questionnaire was revised based on the feedback of the participating exchanges. After the first round of revision and for further validation, the survey was then pre-tested with two more exchanges and again refined. To ensure high awareness and to increase the likelihood of a response, the contact with the exchanges was administered through the WFE, who contacted the senior management within each exchange.

In total, 72 trading venues were contacted and 44 answered the web-based questionnaire between April and June 2016. Forty-two responses came from WFE members, one from a European non-member exchange, and one from a European Multilateral Trading Facility (MTF). A list of all participating trading venues is provided in Appendix A.

This survey focuses on stocks (equity), stock options and index futures and respondents were asked to describe their most relevant circuit breaker mechanisms for their cash market and their derivatives market. If more than one circuit breaker is triggered on a single-instrument basis, participants were asked to give preference to single-instrument trading halts and volatility interruptions compared to order rejection mechanisms.

Due to specific market characteristics, we analyze circuit breaker mechanisms on the cash market and the derivatives markets separately. We also provided the possibility for the participating trading venues to answer the questions for each market separately. Therefore, the respective expert of each market was able to answer the questions regarding his field of expertise. As

\footnotetext{
${ }^{3}$ The authors acknowledge financial support from the Frankfurt Institute for Risk Management and Regulation (FIRM) and the E-Finance Lab.

${ }^{4}$ In the following, the terms "exchanges" and "trading venues" are used interchangeably.

${ }^{5}$ As some exchanges did not respond to all questions, the number of answers to each question can vary. Relative numbers in the following always refer to the total number of answers provided to the respective question.
} 
several exchanges operate both cash and derivatives markets, the analysis is done at market level, rather than venue level, unless explicitly stated otherwise.

\section{Participation Concerning Markets and Asset Classes}

This section describes the trading venues that responded to the joint WFE / Goethe University Frankfurt survey in more detail. Both cash and derivatives markets from different geographic regions are included in this analysis.

\subsection{Markets Analyzed}

From a regional perspective, 15 participants (15 WFE members) are from the Asia-Pacific region i.e., $65 \%$ of the WFE members from that region answered the questionnaire. Ten American trading venues (ten WFE members) replied (71\% of the WFE members from that region) and 19 trading venues (17 WFE members) from Europe, Africa, and Middle East responded (65\% of the WFE members from that region).

Based on WFE statistics, the cash markets covered by this survey account for $61 \%$ of total share trading volume in 2015 among WFE member exchanges (WFE, 2015). Furthermore, $68 \%$ of the total volume of single-stock options and $72 \%$ of the total volume of stock market index futures were traded on the derivatives markets of the participating exchanges.
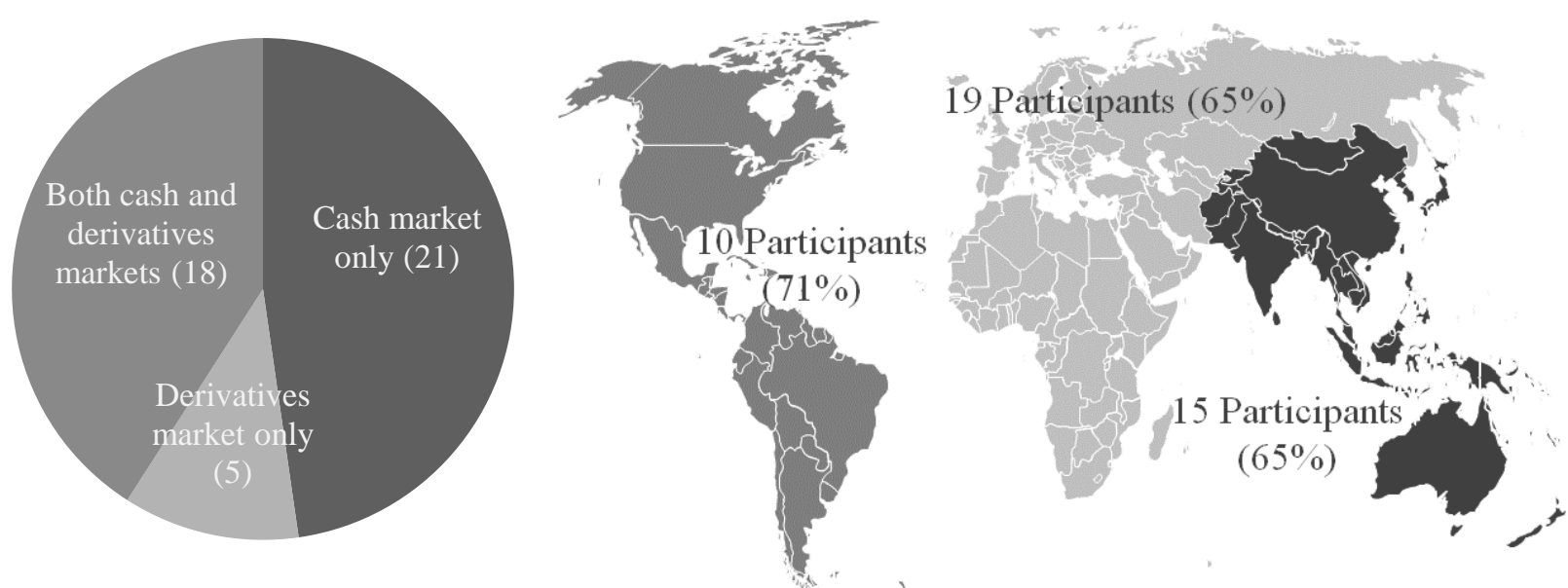

Figure 2: Number of covered trading venues (left) and total number of participants as well as share of represented WFE members per region (right).

Twenty-one of the respondents operate cash markets, five respondents run derivatives markets and 18 operate both market segments (Figure 2). However, three venues running both market segments only answered for their cash market. Therefore, 39 cash markets and 20 derivatives markets are covered in this survey. Appendix E gives an overview of the market models used by the exchanges. 


\subsection{Asset Classes}

All 39 cash markets within our survey provide trading in stocks (Figure 3). Most cash markets offer trading in bonds (85\%) and ETPs (79\%). A much smaller number provide trading for mutual funds (49\%), securitized derivatives (28\%), and currencies (10\%). However, to reduce complexity of the survey, the respondents were asked to consider only blue chip stocks when answering the remainder of the questionnaire for their cash market.

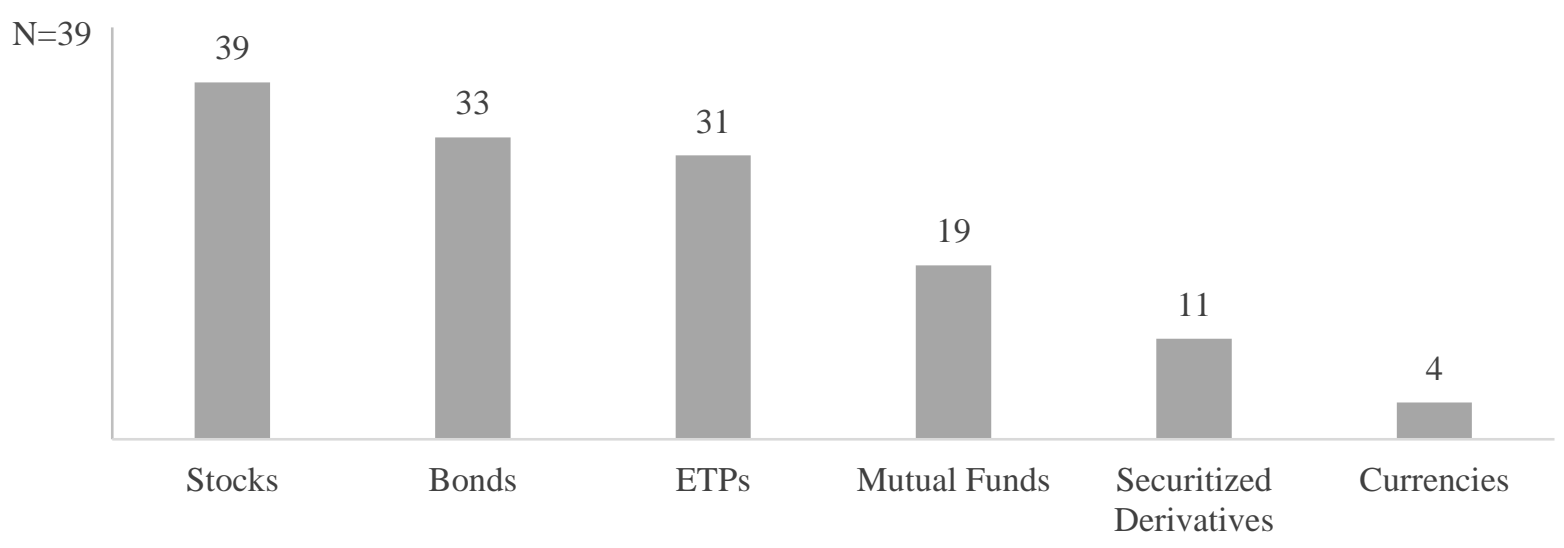

Figure 3: Number of cash markets on which specific asset classes are traded.

Similarly, for the derivatives market segment, the questionnaire focused on stock index futures and stock options. Seventeen derivatives markets in this survey offer trading in both stock index futures and stock options $(85 \%)$ while two venues only trade one of them (each representing another 5\%). Additionally, one venue, which offers only commodity derivatives, answered the questionnaire. About half of the derivatives market venues offer trading in currency $(60 \%)$, interest rate (45\%), commodity (45\%), and Treasury bond derivatives (40\%) besides trading in stock options and index-based derivatives (Figure 4). In line with the cash market, the respondents were asked to consider only stock options and index futures when answering the remainder of the questionnaire.

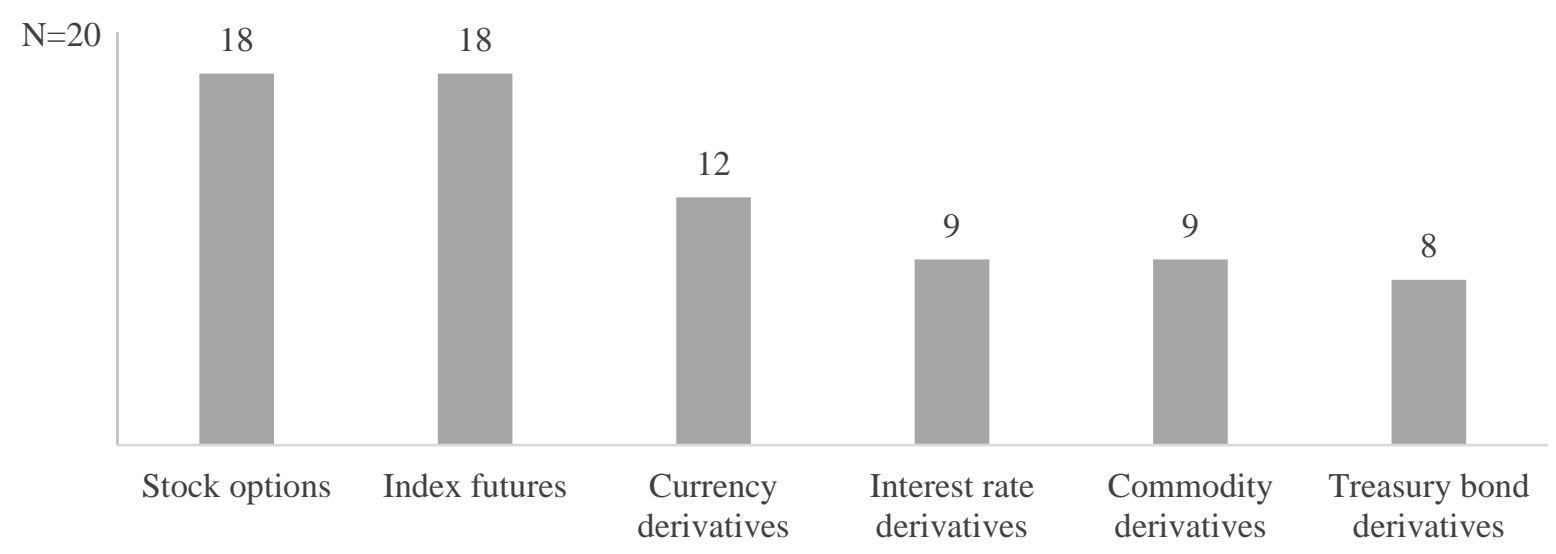

Figure 4: Number of derivatives markets on which specific asset classes are traded. 


\section{Types of Circuit Breaker Implementations}

The following section describes the historical development of circuit breaker implementations and sets out how circuit breakers are used across cash and derivatives markets and venues that operate both markets. Trading venues make use of different types of circuit breakers depending on specific characteristics of their markets and the jurisdiction in which they operate. Additionally, trading venues might combine different types of circuit breakers. Therefore, the report sets out the occurrence of different types of circuit breakers among the venues as well as existing combinations of these mechanisms.

\subsection{Implementation of Circuit Breakers by Market Type and Region}

The first safeguards were implemented between 1988 and 1990. While eight exchanges followed in the 1990s, most venues (22) implemented circuit breakers from 2000 onwards. Eight exchanges introduced circuit breakers after the financial crisis in 2008. The extension of circuit breaker usage among exchanges worldwide documents the expanding efforts of exchanges to enhance investor protection as well as market integrity and stability. The historical development of venues with circuit breakers is depicted in Figure 5. The historical development of circuit breakers per region is provided in Appendix F.

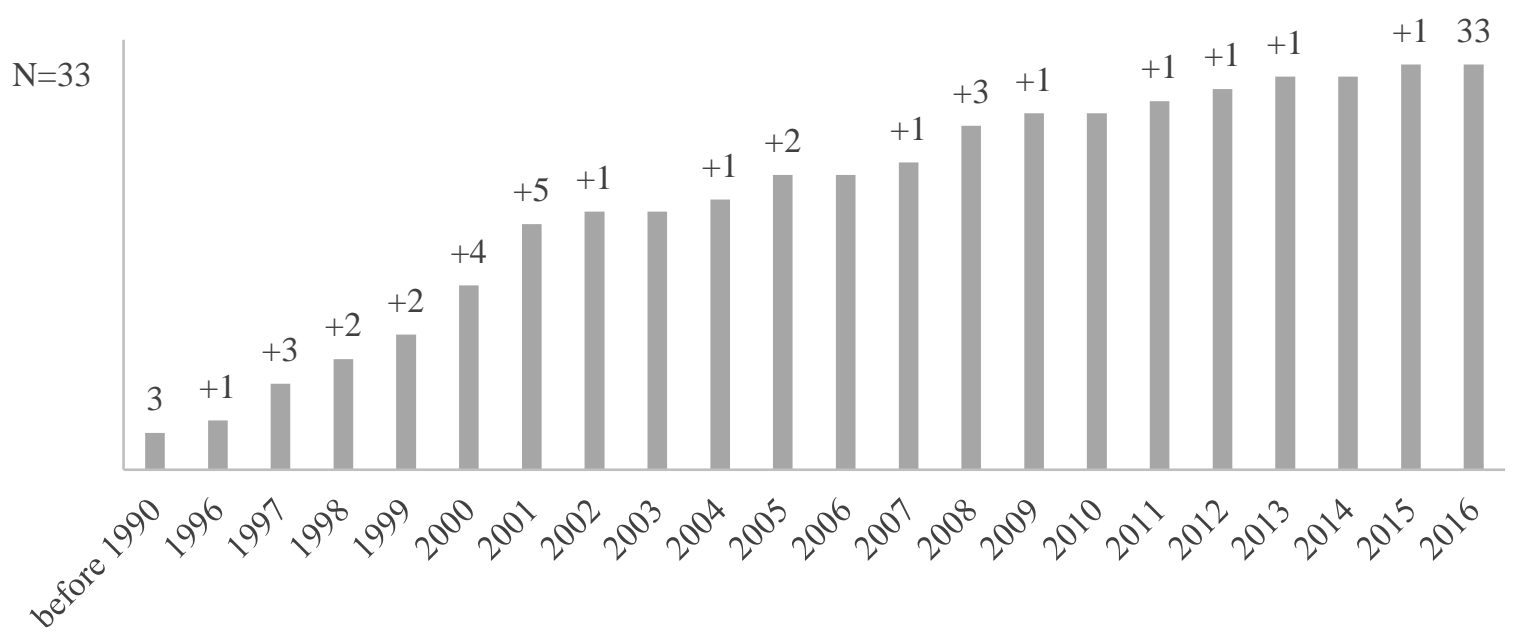

Figure 5: Time sequence of circuit breaker implementation across 33 trading venues (five out of 38 exchanges using circuit breakers did not provide their implementation date). 
Currently, 38 of $44(86 \%)$ trading venues covered in this survey use circuit breakers (Figure 6). Only six survey participants responded that they do not apply any type of circuit breaker mechanism. The tables in Appendices $\mathrm{B}$ and $\mathrm{C}$ provide an overview of responding trading venues with and without circuit breakers, respectively.

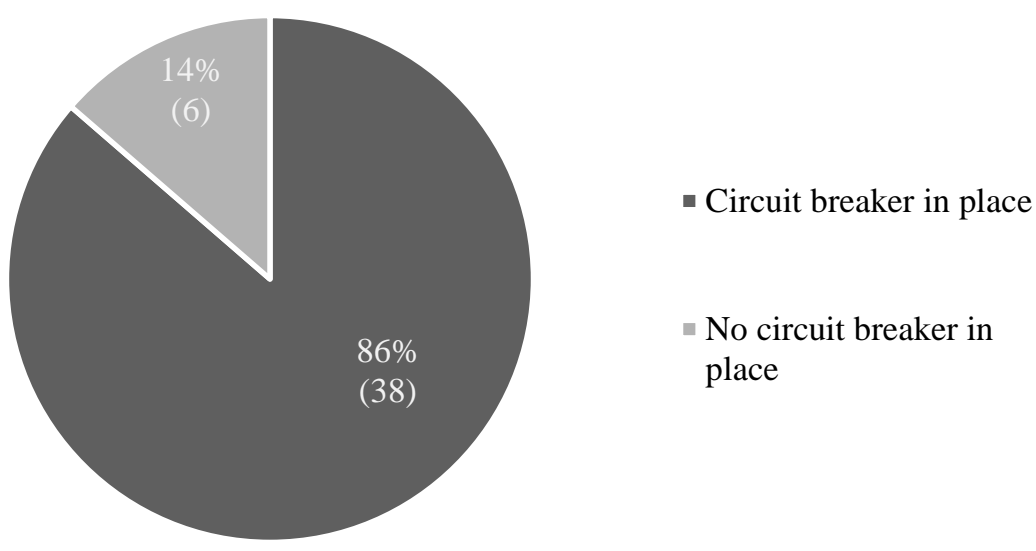

Figure 6: Trading venues with circuit breakers in place.

Breaking down the implementation of circuit breakers to regions, we highlight that in

- Americas: nine of ten (90\%),

- Asia-Pacific: ten of $15(67 \%)$,

- Europe, Africa, and Middle East: 19 of 19 (100\%)

of the considered trading venues have implemented circuit breakers.

Considering the provided market segments, circuit breakers are employed by:

- 18 of $21(86 \%)$ venues that only run cash markets,

- three of five $(60 \%)$ venues that only operate derivatives markets, and

- 17 of $18(94 \%)$ exchanges that operate both market segments.

Turning the view to the cash and derivatives markets themselves, we find that

- 35 out of 39 (90\%) cash markets in the survey apply circuit breakers. Additionally, two cash markets plan to implement circuit breakers in the future. One cash market wants to launch its circuit breaker in 2016 while the other one has no definite time schedule.

- 13 out of the $20(65 \%)$ derivatives markets that answered the survey (three venues that operate both markets did not answer for their derivatives market) have implemented circuit breakers. 
It is worth taking a closer look at the 15 exchanges that operate both cash and derivatives markets and answered the questionnaire for both market segments. Among these, we observe three different ways of managing circuit breakers on the respective derivatives market (see Table 1).

\begin{tabular}{|l|l|l|}
\hline \multicolumn{1}{|c|}{$\begin{array}{l}\text { Coordination between cash and } \\
\text { derivatives market }\end{array}$} & \multicolumn{1}{|c|}{$\begin{array}{c}\text { Separate circuit breaker } \\
\text { implemented on derivatives } \\
\text { market }\end{array}$} & $\begin{array}{r}\text { No circuit breaker on } \\
\text { derivatives market }\end{array}$ \\
\hline $\begin{array}{l}\text { BSE India } \\
\text { Intercontinental Exchange (NYSE) } \\
\text { Nasdaq U.S. }\end{array}$ & $\begin{array}{l}\text { Deutsche Börse } \\
\text { Japan Exchange } \\
\text { NSE India }\end{array}$ & $\begin{array}{l}\text { Moscow Exchange } \\
\text { Barsaw Stock Exchange Stock Exchange }\end{array}$ \\
$\begin{array}{l}\text { Stock Exchange of Thailand* } \\
\text { Tel-Aviv Stock Exchange }\end{array}$ & $\begin{array}{l}\text { Bolsa de Valores de Colombia } \\
\text { Hong Kong Exchanges and Clearing } \\
\text { Johannesburg Stock Exchange }\end{array}$ \\
\hline
\end{tabular}

Table 1: Circuit breakers on derivatives markets of exchanges that serve both market segments. * The Stock Exchange of Thailand coordinates circuit breakers for stock market index futures and single-stock futures. For other derivative products distinct circuit breakers are used.

- Six exchanges coordinate circuit breakers between the cash and the derivatives market.

- Four exchanges employ separate, distinct mechanisms on their derivatives markets

- Five exchanges apply no circuit breaker on their derivatives market, though four exchanges from this third group indicated that they are currently planning to implement circuit breakers for their derivatives market within the next one to three years.

\subsection{Types of Circuit Breakers Implemented at Cash and Derivatives Markets}

Circuit breakers are either triggered based on price movements of an index or of single securities. Therefore, it is possible that trading venues apply different types of circuit breakers making use of these different triggers. As trading venues can implement different types of circuit breakers, multiple answers are possible regarding which circuit breakers are used at specific cash and derivatives markets.

\section{Circuit breaker mechanisms at cash markets}

The 35 cash markets included in this section of the survey employ at least 47 distinct circuit breaker mechanisms. This is because 12 of these markets make use of two alternative mechanisms covered by this survey, e.g. one circuit breaker based on index movements and one triggered by single-stock price fluctuations. 


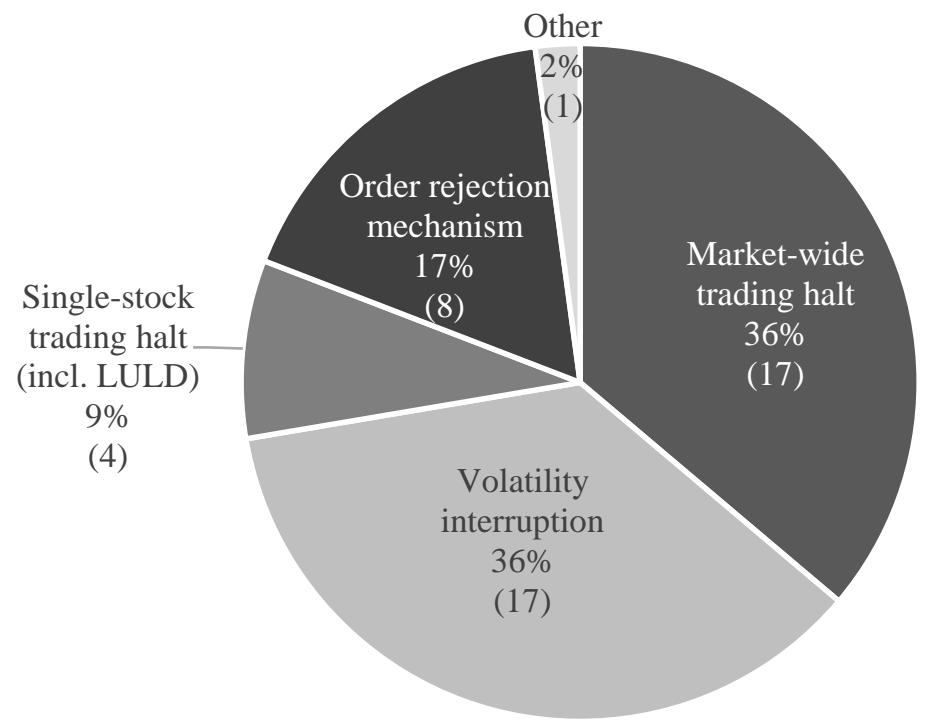

Figure 7: Implemented circuit breaker types on cash markets (the figure is based on 47 distinct mechanisms that were observed in the course of the study).

As depicted in Figure 7, the most widely used mechanisms are volatility interruptions (call auction phases that suspend continuous trading or extend an already ongoing call auction) and market-wide trading halts (both implemented 17 times). Order rejection mechanisms are employed by eight exchanges as their most relevant volatility safeguard ${ }^{6}$, whereas on four cash markets a circuit breaker induces a single-stock trading halt (this category includes limit uplimit down mechanisms, LULD).

Market-wide trading halts are used globally and occur most often in the Asia-Pacific region. Volatility interruptions are mainly observed in Europe, Africa, and the Middle East region (twelve cash markets) with most of the volatility interruptions implemented in Europe (nine cases). Four respondents from the Americas ${ }^{7}$ employ volatility interruptions as well as one venue from the Asia-Pacific region. Single-stock trading halts are implemented in the Americas, as well as the Africa and the Middle East region. No single-stock trading halts are implemented on responding European venues. Order rejection mechanisms are used in three exchanges in the Middle East, one European MTF, and four exchanges in Asia-Pacific (Table 2).

\footnotetext{
${ }^{6}$ In this survey, the respondents were asked to describe their most relevant circuit breaker. Volatility interruptions and single-instrument trading halts were given preference compared to order rejection mechanisms. Consequently, markets with volatility interruptions or single-instrument trading halts might also additionally make use of order rejections.

${ }^{7}$ Bolsa Mexicana de Valores applies a combination of single-stock trading halt (triggered by static thresholds) and volatility interruption (triggered by dynamic thresholds) for the stock-triggered circuit breaker. In the following, this single-stock circuit breaker is counted as a volatility interruption.
} 


\begin{tabular}{|c|c|c|c|c|c|}
\hline Region & $\begin{array}{c}\text { Market-wide } \\
\text { trading halt }\end{array}$ & $\begin{array}{c}\text { Volatility } \\
\text { interruption }\end{array}$ & $\begin{array}{c}\text { Single-stock trading } \\
\text { halt (incl. LULD) }\end{array}$ & $\begin{array}{c}\text { Order rejection } \\
\text { mechanism }\end{array}$ & Total \\
\hline Americas & 5 & 4 & 2 & - & 11 \\
\hline Asia-Pacific & 7 & 1 & - & 4 & 12 \\
\hline $\begin{array}{c}\text { Europe, Africa, } \\
\text { Middle East }\end{array}$ & 5 & 12 & 2 & 4 & 23 \\
\hline Total & 17 & 17 & 4 & 8 & $\mathbf{4 6}$ \\
\hline
\end{tabular}

Table 2: Regional allocation of circuit breaker mechanisms on cash markets (allocation on the basis of monthly WFE reports (WFE, 2015); Japan Exchange Group not included as it employs a unique circuit breaker on their cash market $\left.{ }^{8}\right)$.

Figure 8 shows in which combinations the specific mechanisms are currently employed on the 35 cash markets that apply circuit breakers.

- Twelve of 35 cash markets make use of volatility interruptions as their only circuit breaker mechanism.

- Twelve cash markets rely on market-wide trading halts in combination with an alternative single-stock circuit breaker. Specifically, market-wide trading halts are combined with:

○ volatility interruptions in five cases,

○ single-stock trading halts in four cases and

○ order rejection mechanisms in three cases.

- Five cash markets have implemented a market-wide trading halt as the only circuit breaker.

- Five cash markets rely only on order rejection mechanisms.

\footnotetext{
${ }^{8}$ Japan Exchange has implemented special quote periods and sequential trade quotes to avoid inappropriate price fluctuations. Sequential trade quotes conditions can trigger call auctions with a duration of one minute.
} 


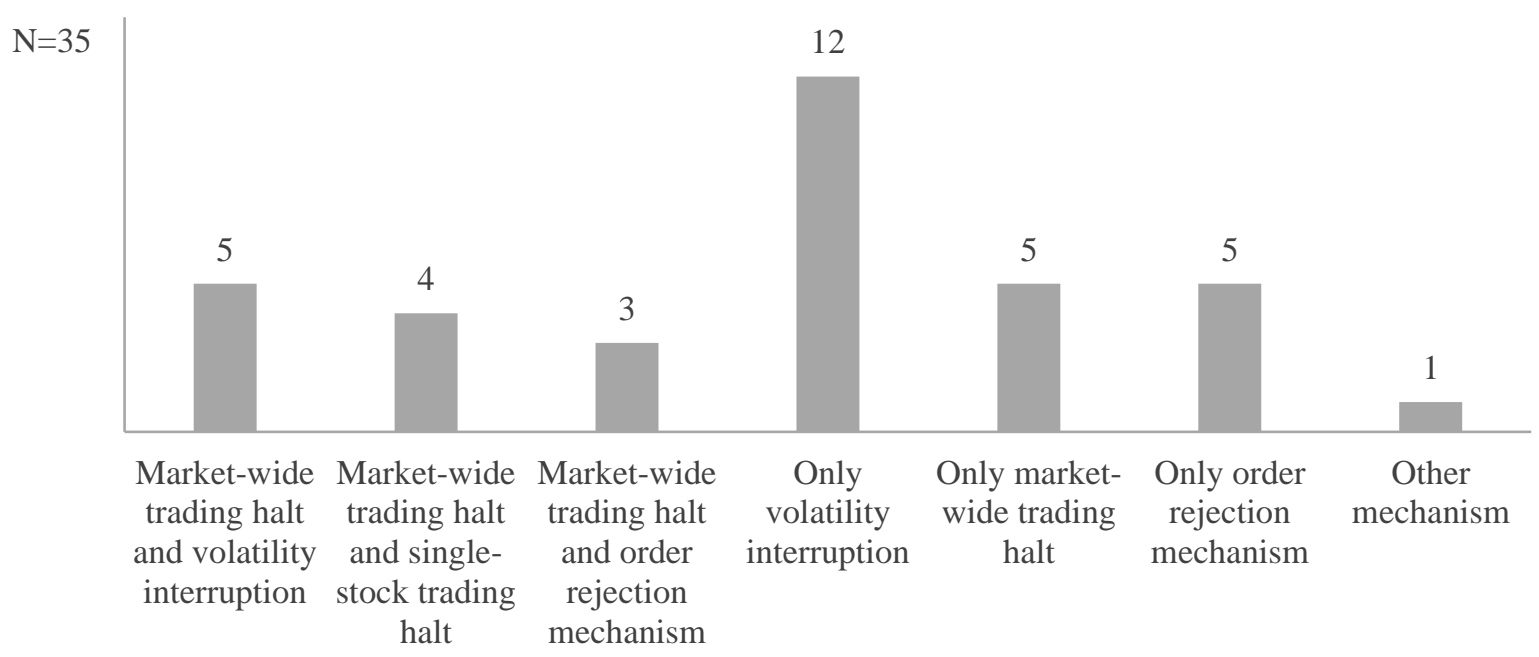

Figure 8: Combination of circuit breaker types on the 35 cash markets that apply circuit breakers.

\section{Circuit breaker mechanisms at derivatives markets}

Figure 9 depicts the circuit breaker mechanisms implemented at the derivatives markets. Six venues coordinate the circuit breaker with their cash market. Coordination with the internal cash market means trading in a derivative is halted or suspended if the underlying on the cash market of the exchange is affected by a circuit breaker. Three venues use both market-wide and individual contract trading halts. Volatility interruptions are implemented on two derivatives markets whereas an order rejection mechanism is only used once. Similar to the cash markets, two of the 13 derivatives markets make use of two circuit breakers, i.e. one triggered by index / index future movements and one based on price fluctuations in individual contracts (leading to 15 mechanisms).

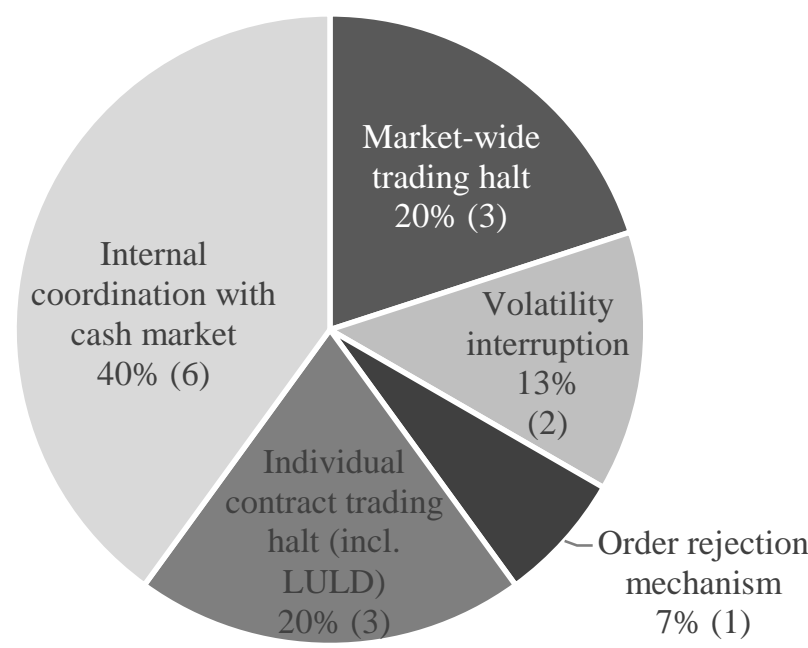

Figure 9: Implemented circuit breaker types on derivatives markets (the figure is based on 15 mechanisms).

When considering regional characteristics of derivatives market circuit breakers, we observe a similar trend to that in the cash markets, i.e., European markets prefer volatility interruptions 
while Americas exchanges prefer market-wide trading halts. Table 3 provides an overview of the regional distribution of circuit breakers on derivatives markets.

\begin{tabular}{|c|c|c|c|c|c|c|}
\hline Region & $\begin{array}{c}\text { Market-wide } \\
\text { trading halt }\end{array}$ & $\begin{array}{c}\text { Volatility } \\
\text { interruption }\end{array}$ & $\begin{array}{c}\text { Single-stock } \\
\text { trading halt } \\
\text { (incl. LULD) }\end{array}$ & $\begin{array}{c}\text { Order } \\
\text { rejection } \\
\text { mechanism }\end{array}$ & $\begin{array}{c}\text { Internal } \\
\text { coordination } \\
\text { with cash } \\
\text { market }\end{array}$ & Total \\
\hline Americas & 2 & - & 1 & - & 2 & 5 \\
\hline $\begin{array}{c}\text { Asia- } \\
\text { Pacific }\end{array}$ & 1 & - & 1 & 1 & 3 & 6 \\
\hline $\begin{array}{c}\text { Europe, Africa, } \\
\text { Middle East }\end{array}$ & - & 2 & 1 & - & 1 & 4 \\
\hline Total & 3 & 2 & 3 & 1 & 6 & $\mathbf{1 5}$ \\
\hline
\end{tabular}

Table 3: Regional allocation of circuit breaker mechanisms on derivatives markets (Regional allocation on the basis of monthly WFE reports (WFE, 2015)).

Figure 10 presents in which combination circuit breakers are currently employed on 13 (out of 20) participating derivatives markets that apply circuit breakers:

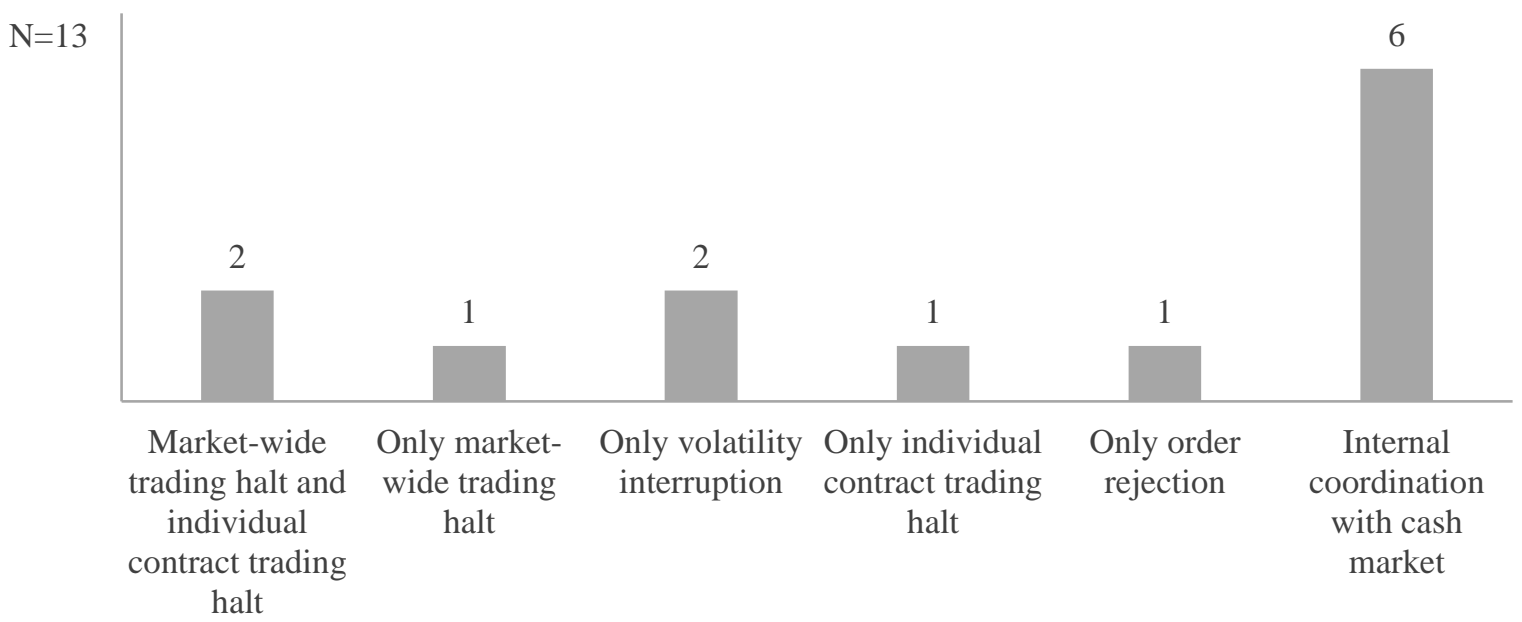

Figure 10: Combination of circuit breaker types on the 13 derivatives markets that apply circuit breakers.

- Six exchanges coordinate the mechanism of their cash markets and their derivatives market.

- The seven remaining venues use circuit breakers as follows:

○ Two venues have implemented market-wide and individual contract trading halts,

○ One venue uses only a market-wide trading halt,

- One venue uses only an individual contract trading halt,

○ Two venues rely on volatility interruptions, and

- One has an order rejection mechanism in place. 


\section{$5 \quad$ Triggering Processes of Circuit Breakers}

This section sheds lights on how circuit breakers are triggered at the participating exchanges. First, possible market movements that cause circuit breakers are presented. Second, the concept of dynamic and static thresholds as well as their occurrence are discussed. Thereafter, price ranges that are set by the exchanges are listed. The last subsection provides details on the parametrization and duration of circuit breakers on the venues covered in this study.

\subsection{Triggering Conditions}

As previously described, circuit breakers may be triggered by index or individual security movements. Respondents were asked to consider only their most relevant circuit breaker for each trigger option. Figure 11 shows that 18 of 35 cash markets with circuit breakers in place refer only to single-stock movements, i.e. circuit breakers are activated due to price movements of individual stocks. Five cash markets use circuit breakers that are triggered by index movements. Twelve cash markets employ both mechanisms, i.e. index as well as single-stock movements can trigger circuit breakers.

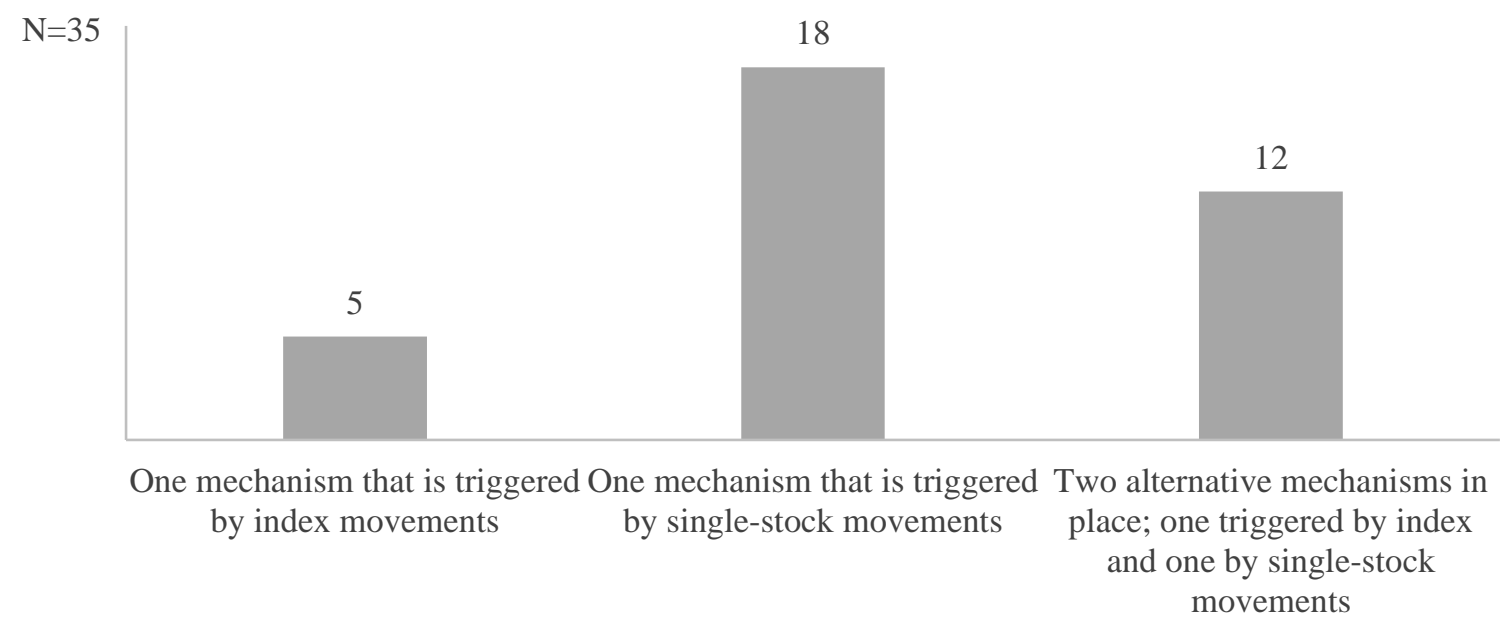

Figure 11: Overview on triggers of circuit breakers on cash markets.

Of the seven derivatives markets that do not coordinate with their internal cash market but make use of a separate circuit breaker for derivatives, four markets refer only to individual contract movements when determining whether or not to trigger a circuit breaker. Only one derivatives market uses circuit breakers that are triggered by index / index futures movements and two markets employ both mechanisms (Figure 12). 


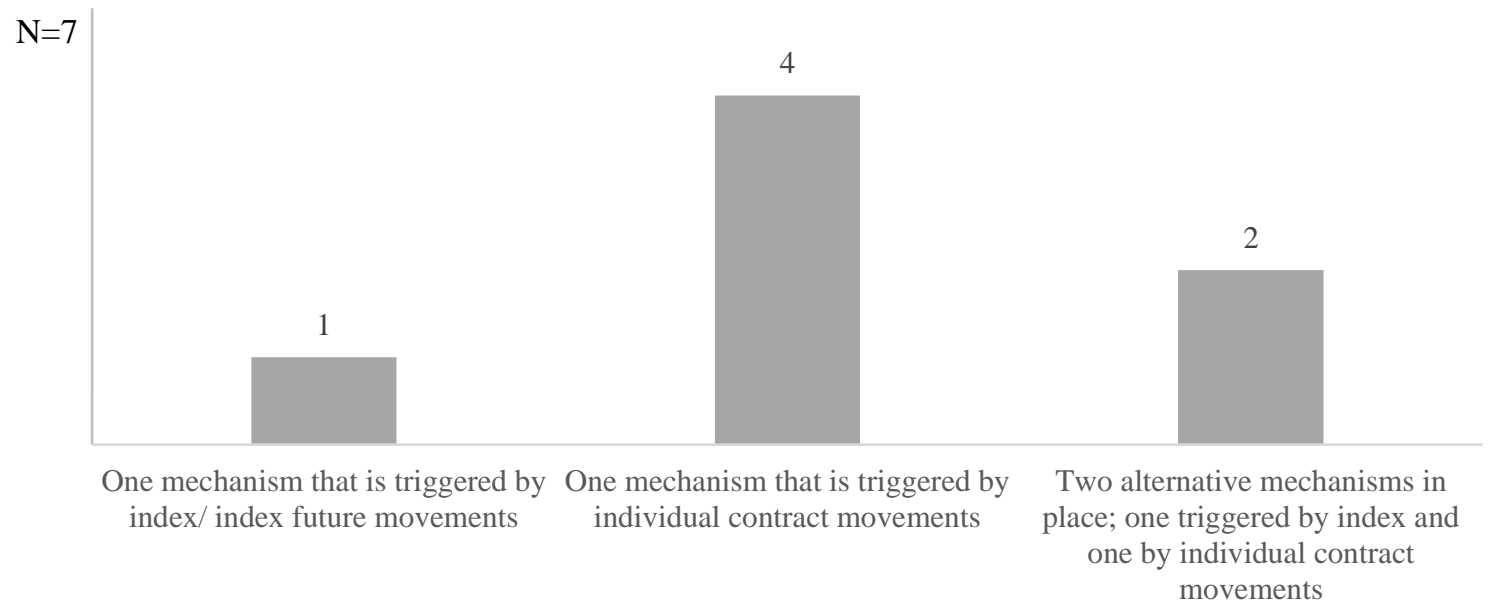

Figure 12: Overview on triggers of circuit breakers on derivatives markets.

In this section, we discuss the direction of market movements (downward and / or upward) that triggers the respective circuit breakers. All 17 index triggered circuit breakers on cash markets reference the main market index and trigger a market-wide trading halt when predetermined thresholds are exceeded or met. Thirteen of those 17 mechanisms only halt trading in response to downward market movements, whereas in the other four markets, trading may also be halted when the index increases. Conversely, 28 out of 30 stock triggered circuit breakers are activated when either upper or lower limits are breached (Figure 13).

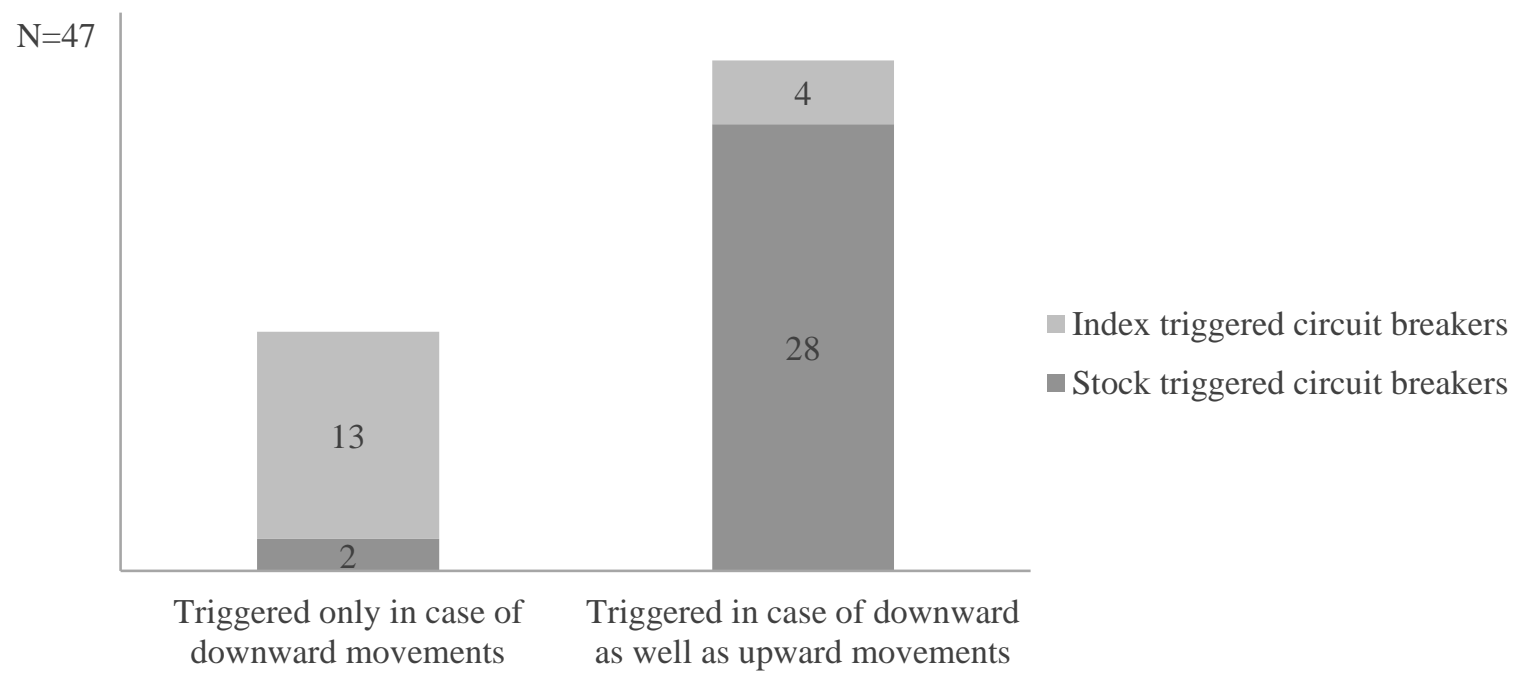

Figure 13: Market directions in which cash market circuit breakers are triggered.

In line with the cash market, the majority of circuit breakers on the derivatives markets are triggered both in upward as well as in downward market movements. Only in two cases, where the circuit breaker on the derivatives market is coordinated with the exchange's cash market, circuit breakers are only activated in downward market movements (see Figure 14). 


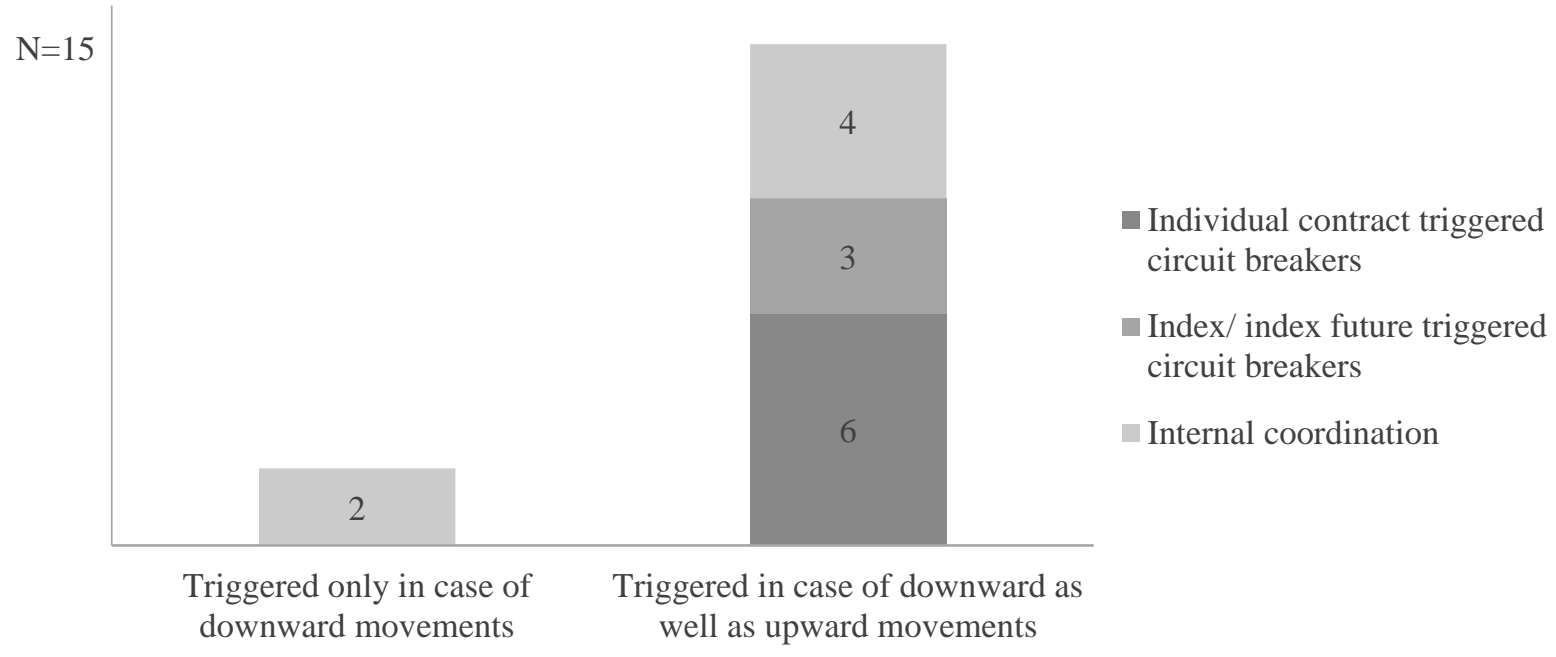

Figure 14: Market directions in which derivatives market circuit breakers are triggered.

\subsection{Triggering Thresholds}

Concerning the triggering rules, we did not observe any discretionary circuit breakers. All cash market mechanisms are triggered when price thresholds are met or exceeded. Trading venues use two different types of threshold determination processes.

All of the 47 circuit breaker mechanisms used in cash markets (see Figure 7) are activated when predetermined price thresholds are met or exceeded. Such price ranges may either be determined:

- using a static price range relative to a specific reference price, e.g., the last day's closing price or the last auction price, or

- using a dynamic price range relative to the last trade price or a moving average of last trade prices.

Dynamic price ranges are updated during the trading day while static ranges are calculated only once or after each auction. Only two mechanisms determine price thresholds based on a computational model. In both cases, the respective circuit breaker is triggered by single-stock movements and leads to a volatility interruption. 
Interestingly, all 17 market-wide trading halts utilize static price ranges. Three stock triggered circuit breakers rely solely on dynamic price ranges while twelve use only static thresholds ${ }^{9}$ (Figure 15). Fifteen stock triggered circuit breaker apply both types of price ranges.

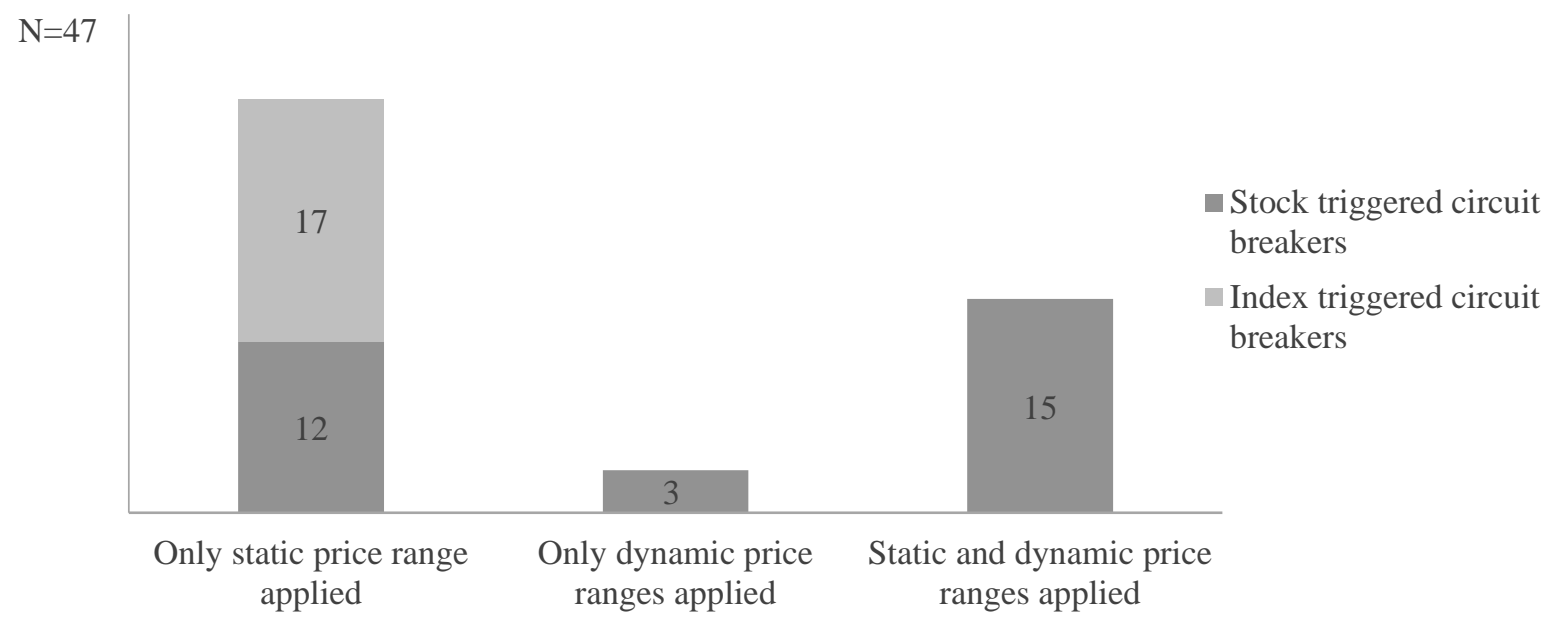

Figure 15: Types of price ranges applied for the triggering process of circuit breakers on cash markets.

Similar to the cash markets, all circuit breakers on the derivatives markets are triggered when price thresholds are met or exceeded (either thresholds of derivatives for distinct derivative circuit breakers or thresholds of cash instruments for internally coordinated circuit breakers). However, different to the cash market, five of the nine distinct circuit breakers on the derivatives markets determine thresholds based on computational models while the other four mechanisms use predetermined price ranges. This might be due to faster moving prices of many derivatives so that predetermined price ranges might not be as appropriate as for stocks.

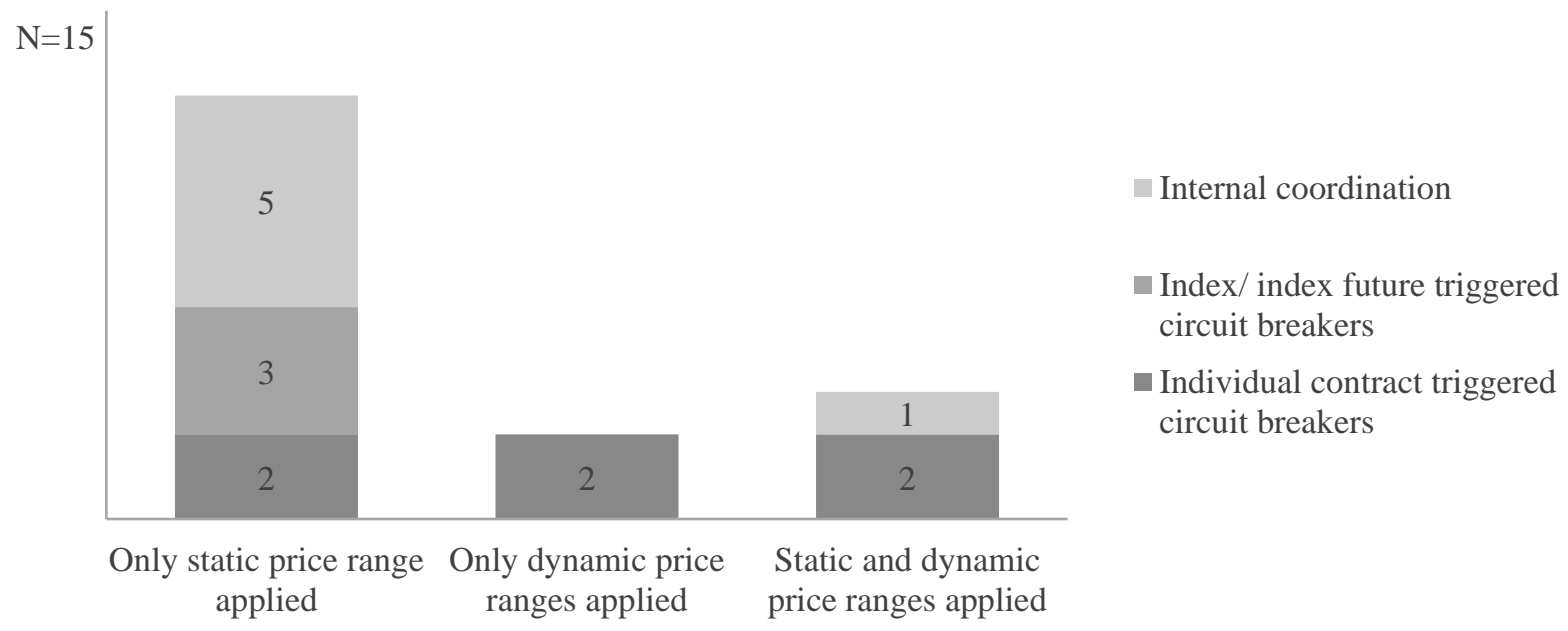

Figure 16: Types of price ranges applied for the triggering process of circuit breakers on derivatives markets.

\footnotetext{
${ }^{9}$ See Table 4 - Table 7 for exchange specific information on static and dynamic price ranges.
} 
As shown in Figure 16, the majority of the 15 derivatives market circuit breakers (see Figure 9) is triggered by exceeded or met static price ranges. This is particularly true when circuit breakers are internally coordinated with the cash market (five out of six cases). Additionally, all three index / index future triggered circuit breakers and two individual contract triggered circuit breakers use static price ranges. Two individual contract circuit breakers are based solely on dynamic price ranges while one internally coordinated circuit breaker and another two individual contract circuit breakers rely on both static and dynamic price ranges.

\subsection{Price Ranges}

When looking at the width of price ranges ${ }^{10}$, it is obvious that dynamic price ranges are set significantly narrower than static price ranges. The eleven dynamic price ranges on cash markets used by volatility interruptions are within $7.5 \%$ in relation to the reference price. Three order rejection mechanisms apply dynamic price ranges between $7.6 \%$ and $10 \%$. The majority of static ranges, on the other hand, are wider than $7.6 \%$ (Figure 17).

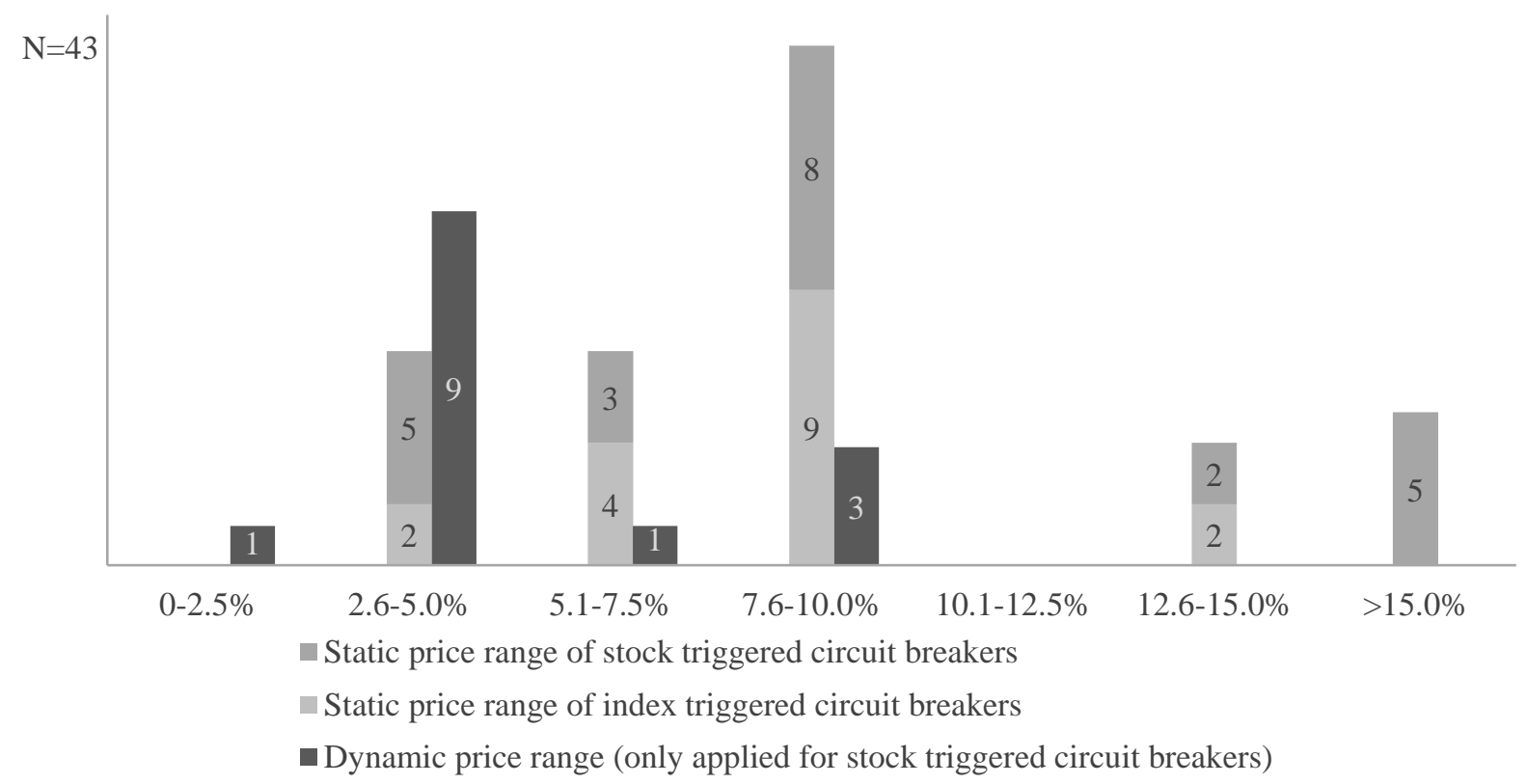

Figure 17: Comparison of the width of static and dynamic price ranges of cash market circuit breakers.

The width of static price ranges applied for index and stock triggered circuit breakers does not differ significantly. However, the two widest static price ranges are observed for order rejec-

\footnotetext{
${ }^{10}$ For stock triggered circuit breakers only price ranges for blue chips are considered. Furthermore, some respondents indicated that several levels of price ranges apply. That is, the higher the level, the wider the ranges and the longer the duration of the circuit breaker. However, for comparing the width of ranges, only first level ranges are considered.
} 
tions, i.e., stock triggered mechanisms. As four respondents apply no general range for blue chip stocks, they are not included in Figure 17 which consequently represents 43 out of the 47 circuit breakers observed on cash markets. ${ }^{11}$

For the circuit breakers on the derivatives markets that are not coordinated with cash markets, the thresholds vary between $7 \%$ and $10 \%$ for the static threshold. One venue triggers individual contract halts for a short period of 30 seconds if the price deviates $0.8 \%$ from the midpoint of the immediate best bid and offer. Three of the nine circuit breakers on derivatives markets that are not coordinated with the respective internal cash market are triggered if individual thresholds, which are calculated by a computational model, are exceeded ${ }^{12}$.

\subsection{Parametrization and Duration of Circuit Breakers}

Respondents were also asked about the duration and potential extensions of circuit breakers. By definition, this is not applicable to order rejection mechanisms.

\section{Market wide trading halts - cash markets}

Table 4 presents the duration of the observed market-wide circuit breakers per exchange in relation to the respective static price range. Some markets differentiate between a market-wide circuit breaker that is triggered during a scheduled auction in the beginning of a trading day and one that is triggered during continuous trading. To facilitate comparability, only parameters during continuous trading are considered. Six of 17 respondents with market-wide trading halts on the cash market rely on one price level that triggers the circuit breaker. The other eleven venues define more than one price level for a market-wide trading halt with six exchanges specifying three levels.

A breach of a first level threshold results in halts that last between 15 minutes to one hour. One cash market halts trading for the rest of the day when the first level threshold is breached. If a second price level is breached, trading is halted for at least 15 minutes and in five markets, this second level breach might suspend trading for the rest of the day. For two venues, this depends on the time when the circuit breaker is triggered. In the other three markets, a level two limit hit always halts trading for the rest of the day. All level three triggers observed in this study

\footnotetext{
${ }^{11}$ Due to the fact that eleven mechanisms in this figure apply both static and dynamic ranges, 54 price ranges are depicted. The four respondents that use stock-specific price ranges apply both static and dynamic ranges.

${ }^{12}$ Due to the low number of responses to this question, no additional figure is depicted here.
} 
lead to a trading halt for the rest of the day. Interestingly, all venues also set the level three price ranges at the same percentage, i.e., at $20 \%$ price movement of the relevant index.

\begin{tabular}{|c|c|c|c|c|}
\hline Exchange & & Level 1 & Level 2 & Level 3 \\
\hline \multirow{2}{*}{ BM\&FBOVESPA } & Threshold & $10 \%$ & $15 \%$ & - \\
\hline & Duration & $30 \mathrm{~min}$ & 1 hour & - \\
\hline \multirow{2}{*}{$\begin{array}{l}\text { Bolsa de Valores } \\
\text { de Lima }\end{array}$} & Threshold & $7 \%$ & $10 \%$ & - \\
\hline & Duration & $15 \min$ & rest of day & - \\
\hline \multirow{2}{*}{$\begin{array}{l}\text { Bolsa Mexicana de } \\
\text { Valores }\end{array}$} & Threshold & $7 \%$ & - & - \\
\hline & Duration & $15 \mathrm{~min}$ & - & - \\
\hline \multirow[b]{2}{*}{ BSE India } & Threshold & $10 \%$ & $15 \%$ & $20 \%$ \\
\hline & Duration & $\begin{array}{r}45 \min (\text { until } 1 \mathrm{pm}) \\
15 \min (1-2: 30 \mathrm{pm}) \\
\text { after } 2: 30 \mathrm{pm} \text { no halt }\end{array}$ & $\begin{array}{r}1: 45 \mathrm{~h} \text { (until 1pm) } \\
45 \mathrm{~min}(1-2: 30 \mathrm{pm}) \\
\text { rest of day (after } 2: 30 \mathrm{pm})\end{array}$ & rest of day \\
\hline \multirow{2}{*}{ Bursa Malaysia } & Threshold & $10 \%$ & $15 \%$ & $20 \%$ \\
\hline & Duration & 1 hour & 3.5 hours & rest of day \\
\hline \multirow{2}{*}{$\begin{array}{l}\text { Colombo Stock } \\
\text { Exchange }\end{array}$} & Threshold & $5 \%$ & - & - \\
\hline & Duration & $30 \mathrm{~min}$ & - & - \\
\hline \multirow{2}{*}{$\begin{array}{l}\text { Intercontinental } \\
\text { Exchange (NYSE) }\end{array}$} & Threshold & $7 \%$ & $13 \%$ & $20 \%$ \\
\hline & Duration & $15 \mathrm{~min}$ (before $3: 25 \mathrm{pm}$ ) & $15 \mathrm{~min}$ (before $3: 25 \mathrm{pm}$ ) & rest of day \\
\hline \multirow{2}{*}{$\begin{array}{l}\text { Kazakhstan Stock } \\
\text { Exchange }\end{array}$} & Threshold & $15 \%$ & - & - \\
\hline & Duration & rest of day & - & - \\
\hline \multirow{2}{*}{ Korea Exchange } & Threshold & $8 \%$ & $15 \%$ & $20 \%$ \\
\hline & Duration & $20 \min +10 \min$ auction & $20 \min +10 \min$ auction & rest of day \\
\hline \multirow{2}{*}{ Moscow Exchange } & Threshold & $15 \%$ & - & - \\
\hline & Duration & $30 \mathrm{~min}$ & - & - \\
\hline \multirow{2}{*}{ Nasdaq U.S. } & Threshold & $7 \%$ & $13 \%$ & $20 \%$ \\
\hline & Duration & $15 \min$ (before $3: 25 \mathrm{pm}$ ) & $15 \mathrm{~min}$ (before $3: 25 \mathrm{pm}$ ) & rest of day \\
\hline \multirow[b]{2}{*}{ NSE India } & Threshold & $10 \%$ & $15 \%$ & $20 \%$ \\
\hline & Duration & $\begin{array}{r}45 \min (\text { until } 1 \mathrm{pm}) \\
15 \min (1-2: 30 \mathrm{pm}) \\
\text { after } 2: 30 \mathrm{pm} \text { no halt }\end{array}$ & $\begin{array}{r}1: 45 \mathrm{~h} \text { (until 1pm) } \\
45 \mathrm{~min}(1-2: 30 \mathrm{pm}) \\
\text { rest of day (after } 2: 30 \mathrm{pm})\end{array}$ & rest of day \\
\hline \multirow{2}{*}{$\begin{array}{l}\text { Philippine Stock } \\
\text { Exchange }\end{array}$} & Threshold & $10 \%$ & - & - \\
\hline & Duration & $15 \mathrm{~min}$ & - & - \\
\hline \multirow{2}{*}{$\begin{array}{l}\text { Stock Exchange of } \\
\text { Mauritius }\end{array}$} & Threshold & $8 \%$ & - & - \\
\hline & Duration & $15 \mathrm{~min}$ & - & - \\
\hline \multirow{2}{*}{$\begin{array}{l}\text { Stock Exchange of } \\
\text { Thailand }\end{array}$} & Threshold & $10 \%$ & $20 \%$ & - \\
\hline & Duration & $30 \mathrm{~min}$ & $1 \mathrm{~h}$ & - \\
\hline \multirow{2}{*}{$\begin{array}{l}\text { Tel-Aviv Stock Ex- } \\
\text { change }\end{array}$} & Threshold & $8 \%$ & $12 \%$ & - \\
\hline & Duration & $45 \min$ & rest of day & - \\
\hline \multirow{2}{*}{$\begin{array}{l}\text { The Egyptian Ex- } \\
\text { change }\end{array}$} & Threshold & $5 \%$ & $10 \%$ & - \\
\hline & Duration & $30 \mathrm{~min}$ & rest of day & - \\
\hline
\end{tabular}

Table 4: Parametrization of market-wide trading halts on cash markets. 


\section{Single stock trading halts - cash markets}

In total, four exchanges suspend trading in individual stocks when predetermined price ranges are exceeded. The duration of the single-stock trading halt varies from five to 30 minutes. Extensions are possible on three out of four cash markets (Table 5). All exchanges that use singlestock trading halts only apply static thresholds. These vary between 5\% and 30\% though in three of four trading venues the respective circuit breaker is triggered with a $5 \%$ price move.

\begin{tabular}{|c|c|c|c|}
\hline Exchange & & Static range & Extension possible? \\
\hline \multirow{2}{*}{$\begin{array}{l}\text { Intercontinental Exchange } \\
\text { (NYSE) }\end{array}$} & Threshold & $5 \%$ & \multirow{2}{*}{ yes } \\
\hline & Duration & $5 \mathrm{~min}$ & \\
\hline \multirow{2}{*}{ Kazakhstan Stock Exchange } & Threshold & $30 \%$ & \multirow{2}{*}{ no } \\
\hline & Duration & $5 \mathrm{~min}$ & \\
\hline \multirow{2}{*}{ Nasdaq U.S. } & Threshold & $5 \%$ & \multirow{2}{*}{ yes } \\
\hline & Duration & $5 \mathrm{~min}$ & \\
\hline \multirow{2}{*}{ The Egyptian Exchange } & Threshold & $5 \%$ & \multirow{2}{*}{ yes } \\
\hline & Duration & $30 \mathrm{~min}$ & \\
\hline
\end{tabular}

Table 5: Parametrization of single-stock trading halts on cash markets.

\section{Volatility interruptions - cash markets}

Information on duration and potential extension of volatility interruptions is presented in Table 6. The 17 considered volatility interruptions last from one minute to 30 minutes with eleven of those ending randomly before normal trading continues. The duration of a volatility interruption is mostly indifferent as to whether static or dynamic thresholds are breached. Only Nasdaq Nordic and Warsaw Stock Exchange differentiate. Volatility interruptions may be extended on ten out of 17 cash markets. 


\begin{tabular}{|c|c|c|c|c|c|}
\hline Exchange & & Static range & Dynamic range & $\begin{array}{l}\text { Random } \\
\text { end }\end{array}$ & $\begin{array}{l}\text { Extension } \\
\text { possible? }\end{array}$ \\
\hline \multirow{2}{*}{$\begin{array}{l}\text { Athens Stock Ex- } \\
\text { change }\end{array}$} & Threshold & $10 \%$ & $3 \%$ & yes & \multirow{2}{*}{ yes, $3 \mathrm{~min}$} \\
\hline & Duration & $5 \mathrm{~min}$ & & $1 \mathrm{~min}$ & \\
\hline \multirow{2}{*}{ BME } & Threshold & \multicolumn{2}{|c|}{$\begin{array}{l}\text { stock-specifically determined by computa- } \\
\text { tional model }\end{array}$} & yes & \multirow[t]{2}{*}{ no } \\
\hline & Duration & \multicolumn{2}{|c|}{$5 \min$} & $30 \mathrm{sec}$ & \\
\hline \multirow{2}{*}{$\begin{array}{l}\text { Bolsa de Comer- } \\
\text { cio de Santiago }\end{array}$} & Threshold & $10 \%$ & - & yes & \multirow{2}{*}{ yes } \\
\hline & Duration & not determined & - & $30 \mathrm{sec}$ & \\
\hline \multirow{2}{*}{$\begin{array}{l}\text { Bolsa de Valores } \\
\text { Colombia }\end{array}$} & Threshold & $6.5 \%$ & - & yes & \multirow{2}{*}{ no } \\
\hline & Duration & $2: 30 \mathrm{~min}$ & - & $30 \mathrm{sec}$ & \\
\hline \multirow{2}{*}{$\begin{array}{l}\text { Bolsa de Valores } \\
\text { de Lima }\end{array}$} & Threshold & - & $7 \%$ & yes & \multirow{2}{*}{ no } \\
\hline & Duration & - & $5 \mathrm{~min}$ & $2 \mathrm{~min}$ & \\
\hline \multirow{2}{*}{$\begin{array}{l}\text { Bolsa Mexicana } \\
\text { de Valores }\end{array}$} & Threshold & $15 \%^{13}$ & $5 \%$ & not indicated & \multirow{2}{*}{ no } \\
\hline & Duration & $2-20 \mathrm{~min}$ & & - & \\
\hline \multirow{2}{*}{$\begin{array}{l}\text { Cyprus Stock Ex- } \\
\text { change }\end{array}$} & Threshold & $10 \%$ & $3 \%$ & yes & \multirow{2}{*}{ yes, $3 \mathrm{~min}$} \\
\hline & Duration & $5 \mathrm{~min}$ & & $1 \mathrm{~min}$ & \\
\hline \multirow{2}{*}{ Deutsche Börse } & Threshold & $\begin{array}{l}\text { not published; stock-sp } \\
\text { mined by computati }\end{array}$ & $\begin{array}{l}\text { ecifically deter- } \\
\text { onal model }\end{array}$ & yes & \multirow{2}{*}{$\begin{array}{r}\text { yes, man- } \\
\text { ual } \\
\text { termination }\end{array}$} \\
\hline & Duration & $2 \min$ & & $30 \mathrm{sec}$ & \\
\hline \multirow{2}{*}{$\begin{array}{l}\text { Irish Stock Ex- } \\
\text { change }\end{array}$} & Threshold & not publish & & yes & \multirow[b]{2}{*}{ yes } \\
\hline & Duration & $2 \min$ & & - & \\
\hline \multirow{2}{*}{$\begin{array}{l}\text { Johannesburg } \\
\text { Stock Exchange }\end{array}$} & Threshold & $10 \%$ & $3 \%$ & yes & \multirow{2}{*}{ yes, $2 \mathrm{~min}$} \\
\hline & Duration & $5 \mathrm{~min}$ & & $30 \mathrm{sec}$ & \\
\hline \multirow{2}{*}{ Korea Exchange } & Threshold & $10 \%$ & $3 \%$ & not indicated & \multirow{2}{*}{ no } \\
\hline & Duration & $2 \mathrm{~min}$ & & - & \\
\hline \multirow{2}{*}{$\begin{array}{l}\text { Luxembourg } \\
\text { Stock Exchange }\end{array}$} & Threshold & $5 \%$ & $5 \%$ & not indicated & \multirow{2}{*}{$\begin{array}{r}\text { yes, } 1: 30 \\
\min \end{array}$} \\
\hline & Duration & $1: 30 \mathrm{~min}$ & & - & \\
\hline \multirow{2}{*}{$\begin{array}{l}\text { Moscow Ex- } \\
\text { change }\end{array}$} & Threshold & $20 \%$ & - & not indicated & \multirow{2}{*}{ no } \\
\hline & Duration & $30 \mathrm{~min}$ & - & - & \\
\hline \multirow{2}{*}{ Nasdaq Nordic } & Threshold & $5 \%$ & $3 \%$ & yes & \\
\hline & Duration & $3 \mathrm{~min}$ & $1 \mathrm{~min}$ & $5 \mathrm{sec}$ & no \\
\hline SIX Swiss Ex- & Threshold & - & $1.5 \%$ & yes & \\
\hline change & Duration & - & $5 \mathrm{~min}$ & - & yes \\
\hline Tel-Aviv Stock & Threshold & $7 \%$ & $4 \%$ & not indicated & \\
\hline Exchange & Duration & $5-6 \min$ & & - & yes \\
\hline & Threshold & $10 \%$ & $3.5 \%$ & not indicated & \\
\hline Exchange & Duration & $\begin{array}{r}\text { depends on market } \\
\text { conditions }\end{array}$ & mainly $1 \mathrm{~min}$ & - & yes, 1 min \\
\hline
\end{tabular}

Table 6: Parametrization of volatility interruptions on cash markets.

${ }^{13}$ Bolsa Mexicana de Valores triggers a single-stock trading halt if static thresholds are exceeded. A volatility interruption and the corresponding call auction are triggered in case the dynamic threshold is breached. 


\section{Order rejection mechanisms - cash markets}

Regarding the parametrization of order rejection mechanisms, five of eight mechanisms on cash markets are triggered solely with reference to static prices ranges (see Table 7). On two cash markets, both static and dynamic price ranges are applied while one venue only triggers an order rejection based on exceeded dynamic thresholds. The static price ranges vary between $7.5 \%$ and $20 \%$ for the cash markets that only rely on static thresholds. The cash markets that make use of both static and dynamic price ranges reject an order if the static reference price is exceeded by $30 \%$ and $50 \%$, respectively. Dynamic price ranges for order rejection mechanisms vary between $8 \%$ and $10 \%$. As no duration is attributable to order rejection mechanisms, this parameter is not provided.

\begin{tabular}{|l|r|r|}
\hline \multicolumn{1}{|c|}{ Exchange } & Static range & Dynamic range \\
\hline Amman Stock Exchange & $7.5 \%$ & - \\
\hline Aquis & $10 \%$ & $8 \%$ \\
\hline Australian Securities Exchange & - & - \\
\hline Bursa Malaysia & $30 \%$ & - \\
\hline Colombo Stock Exchange & $20 \%$ & $10 \%$ \\
\hline Dubai Financial Market & $15 \%$ up; & - \\
\hline Philippine Stock Exchange & $50 \%$ & down \\
\hline Saudi Stock Exchange & $10 \%$ & \\
\hline
\end{tabular}

Table 7: Parametrization of order rejection mechanisms on cash markets.

\section{Market wide trading halts - derivatives markets}

In the derivatives market segments, three market-wide circuit breakers are implemented ${ }^{14}$. All of them define three triggering levels. At the Japan Exchange, each level triggers a ten minute trading halt, whereas the first two levels on the CME and CBOE last 15 minutes and the third level suspends trading for the rest of the day.

\section{Volatility interruptions - derivatives markets}

One of the two volatility interruptions on derivatives markets triggers a call auction for about one minute depending on the contract and whether static or dynamic price ranges are exceeded.

\footnotetext{
${ }^{14}$ As there are only between one and three distinct circuit breakers per category on the derivatives markets, no separate tables are presented.
} 
When triggered by static thresholds, the call auction takes longer. The other volatility interruption is terminated manually and price ranges, which are based on a computational model, are not disclosed.

\section{Individual contract trading halt - derivatives markets}

Trading halts in individual stock market index futures contracts last only 30 seconds on the Japanese derivatives market while individual contracts, once triggered, are suspended from trading for 15 minutes at Moscow Exchange. At CME, individual contracts go into a twominute monitoring period followed by a two-minute trading halt.

\section{Order rejection mechanisms - derivatives market}

The only order rejection mechanism on derivatives markets has a static range of $10 \%$.

\section{Information Provision on and during Circuit Breakers}

This section describes the nature and extent of information that exchanges provide about circuit breakers. Almost all trading venues disclose the threshold determination process to market participants. Traders can find the relevant information such as the triggering thresholds on the exchanges' website, in trading rule books, or in the market model description. Three exchanges indicated that only selected elements of the process, such as a description of the general model, are publicly available. Of these, two exchanges do not disclose the triggering thresholds as this knowledge may foster potential market manipulation. One exchange responded that while the thresholds are transparent, the model to determine the thresholds is not. Furthermore, these venues argue that market participants might challenge the thresholds if they are publicly known and trigger volatility interruptions on purpose in order to interrupt continuous trading.

When stock prices or indices exceed a threshold and a circuit breaker is triggered, market participants are typically notified via the trading venues' trading systems. Thirty-five of the 38 exchanges that have implemented circuit breakers confirmed that traders are explicitly informed about the activation of a circuit breaker. Two trading venues said that traders are not informed about the activated circuit breaker (one exchange did not provide information concerning this question).

However, depending on the mechanism, different types of information are disclosed while the circuit breaker is activated (Figure 18). Fourteen of the 17 cash markets that have implemented volatility interruptions show traders indicative prices during the call auction phase. Twelve of 
these markets disclose indicative volumes as well ${ }^{15}$. On three cash markets, traders are only informed about the transition to a volatility interruption. During a market-wide trading halt, eight cash markets (out of 17 that have implemented a market-wide trading halt) disclose indicative prices and volumes while four markets communicate the exact duration of the trading suspension in addition to the information that a circuit breaker is active. The remaining five markets using market-wide trading halts just inform market participants about the circuit breaker event. The same applies for two single-stock trading halts while the other three singlestock trading halts that were observed in this study report indicatives prices. Two of them also report indicative volumes. The eight cash markets that employ order rejection mechanisms only inform market participants about rejections.

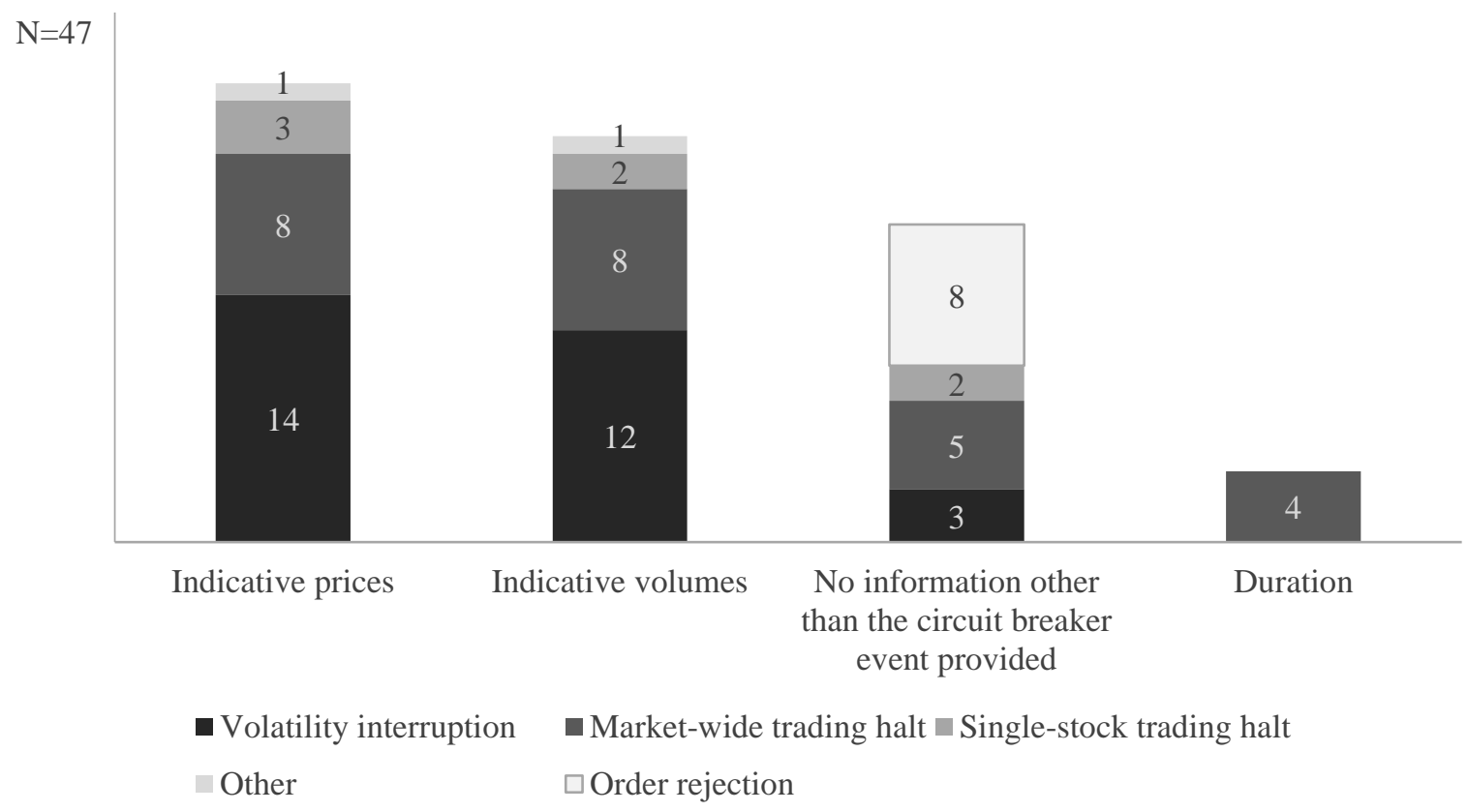

Figure 18: Information provided to market participants during a circuit breaker on the cash market (for one mechanism no information was provided; please consider that multiple types of information may be published per mechanisms).

In the derivatives markets (Figure 19), six of nine circuit breaker mechanisms that are not coordinated with the internal cash market disclose indicative prices and four of them additionally provide indicative volumes. For two of these mechanisms, the respective venue only informs market participants about the length of the trading suspension while one venue with an

\footnotetext{
${ }^{15}$ So does Japan Exchange whose circuit breaker was classified as "other".
} 
individual contract halt provides no information other than the triggering of the circuit breaker itself.

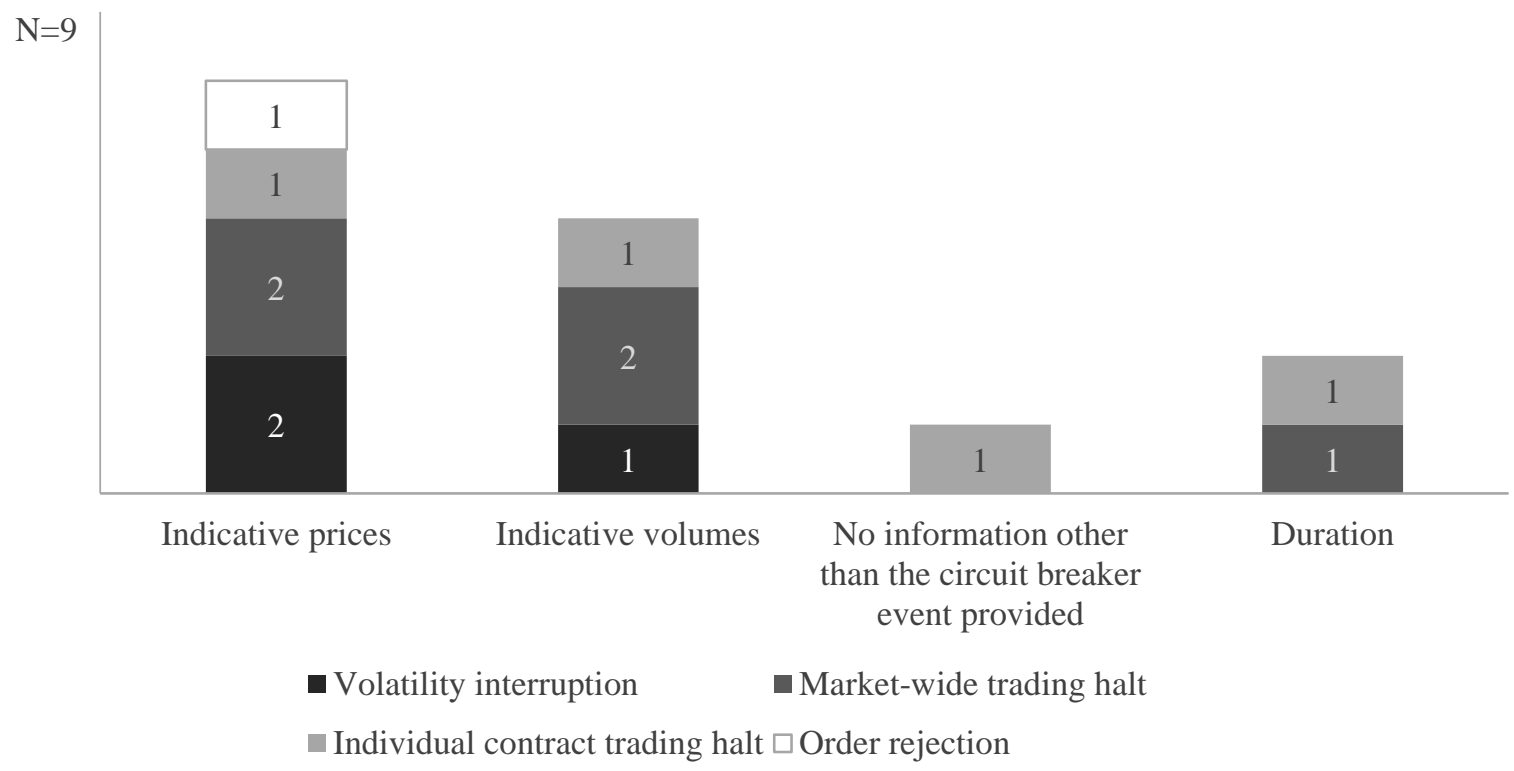

Figure 19: Information provided to market participants during a circuit breaker on the derivatives market.

\section{$7 \quad$ Initiation and Revision of Circuit Breaker Mechanisms}

The legal and regulatory handling of circuit breakers varies among the trading venues that responded to our survey. Twenty-two respondents stated that the implementation of their circuit breakers was initiated by the trading venue itself (Figure 20). Four exchanges followed the initiative of the national regulator and in eleven cases circuit breakers were implemented based on a collaboration of both the exchange and the national regulator ${ }^{16}$.

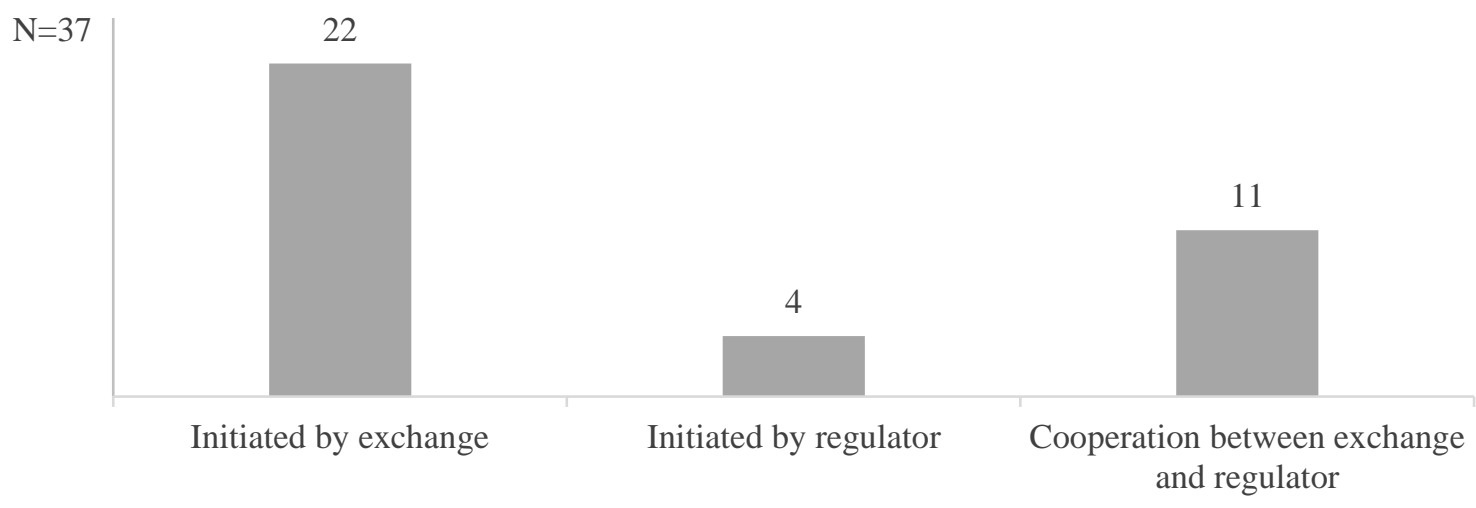

Figure 20: Initiators of circuit breaker implementation (37 respondents out of 38 exchanges applying circuit breakers provided information).

${ }^{16}$ One of the exchanges with circuit breakers did not provide information on who initiated the implementation. 
While most trading venues in the Europe, Africa, and Middle East region (13 of 18 respondents to this question) as well as those in the Asia-Pacific region (seven of ten respondents) indicate that the implementation of circuit breakers was based on exchange internal efforts, trading venues in the Americas region, especially those located in the U.S., explained that the implementation of circuit breakers was the result of cooperation between the exchanges and the respective regulator (six of nine respondents; see Table 8).

\begin{tabular}{|l|c|c|c|c|}
\hline \multicolumn{1}{|c|}{ Region } & Initiated by exchange & Initiated by regulator & $\begin{array}{c}\text { Cooperation between } \\
\text { exchange and regulator }\end{array}$ & Total \\
\hline Americas & 2 & 1 & 6 & 9 \\
\hline Asia-Pacific & 7 & 2 & 1 & 10 \\
\hline $\begin{array}{l}\text { Europe, Africa, } \\
\text { Middle East }\end{array}$ & 13 & 1 & 4 & 18 \\
\hline Total & 22 & 4 & 11 & $\mathbf{3 7}$ \\
\hline
\end{tabular}

Table 8: Regional distribution of the circuit breaker initiator (Regional allocation on the basis of monthly WFE reports (WFE, 2015)).

Regarding the revision and amendment of circuit breakers, almost half of the exchanges (47\%) indicated that this is in their own area of competence. Another $38 \%$ of the respondents share the competence with national regulatory authorities and only in five cases (15\%), regulators are the only decision-makers concerning circuit breaker revisions (Figure 21). Four of the 38 trading venues with circuit breakers did not respond to this question.

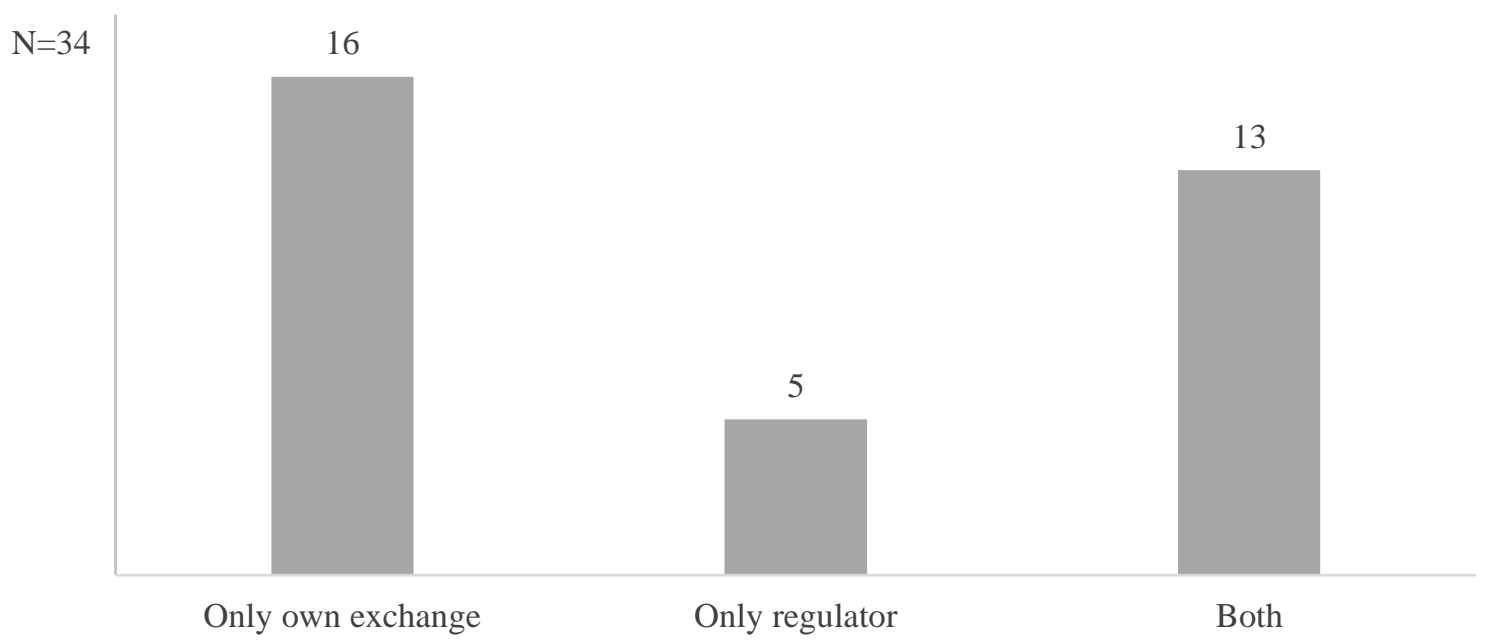

Figure 21: Body in charge for the amendment of circuit breaker mechanisms (34 of 38 exchanges that use circuit breakers answered).

When asked whether the provisions of the circuit breaker mechanism(s) are revised periodically, the majority of exchanges that employ circuit breakers (56\%) said they were not (Figure 22). However, if circuit breakers are periodically revised, they are frequently modified. Twelve of 15 exchanges that regularly review their circuit breakers, amended certain elements in the 
last three years. Most commonly, parameters such as price ranges or duration are adjusted. Also, one exchange defined new classification criteria for stocks. On the other hand, trading venues rarely modify circuit breaker rules due to extraordinary market events. Eight out of 38 venues $(21 \%)$ reacted to external developments in the last five years. In reaction to the financial crisis in 2008 , one venue widened the price ranges that trigger a circuit breaker due to increased volatility on financial markets whereas another venue narrowed price ranges in response to a regulatory initiative. Also, one venue additionally implemented a volatility interruption mechanism to further enhance investor protection.

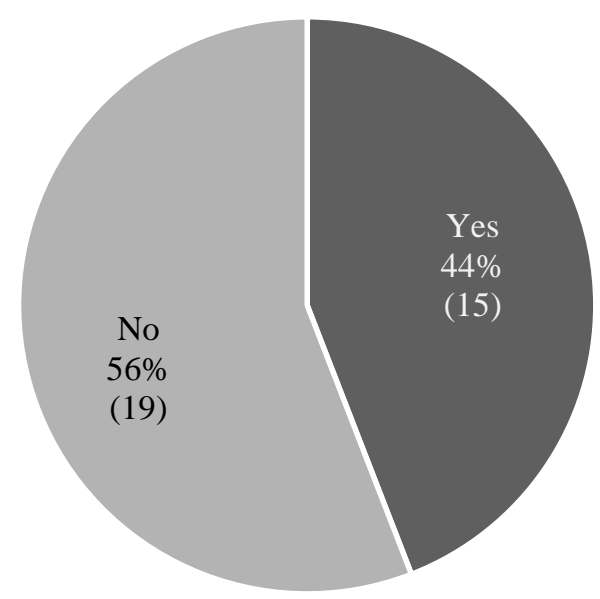

Figure 22: Proportion of exchanges that periodically review their circuit breaker mechanisms.

\section{Coordination of Circuit Breakers}

The survey also covered the topic "coordination of circuit breakers". Different jurisdictions and venues have adopted different approaches (see the proposed revisions of the Markets in Financial Instruments Directive (MiFID II) in Europe and the practice in the US). Therefore, the survey looked at two aspects of coordination:

- Coordination within one exchange between the cash and derivatives markets (this is dealt with in section 4);

- Coordination across trading venues (domestic as well international). 
Twenty-nine respondents answered the question whether they are in favor of or against a coordination of circuit breakers across trading venues ${ }^{17}$. Of these, 20 (69\%) generally favor coordination, four are undecided and five exchanges explicitly reject the concept of coordination as unnecessary or even harmful for the market (Figure 23).

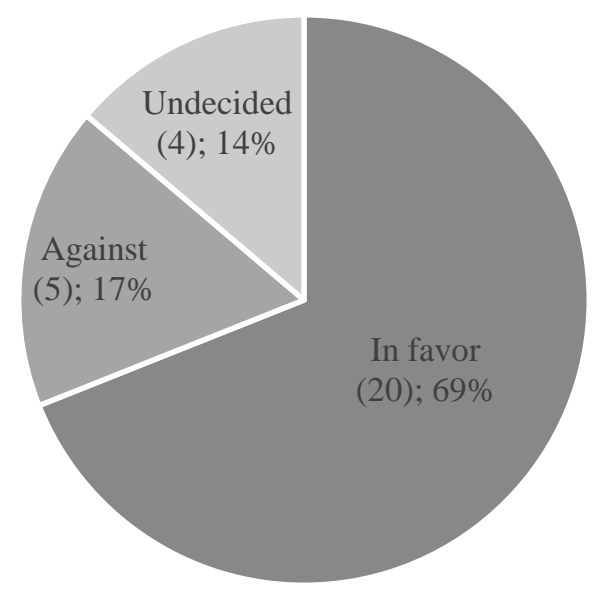

Figure 23: Respondents' general opinion on coordination of circuit breakers (29 respondents provided an answer).

Respondents subsequently had the opportunity to underline their opinion by agreeing to predetermined pro and contra arguments or by expressing additional individual thoughts (multiple answers were possible) ${ }^{18}$. The pro argument put forward by all 24 proponents and undecided respondents is that coordination may enhance investor protection (Figure 24). Furthermore, 22 of 24 respondents in that group agree with the statement that extreme volatility spillovers across trading venues may be prevented. The majority (19 respondents) also believed that coordination could contribute to an improvement in price continuity as well as in a reduction of the risk of future market turmoil (17 respondents). According to 16 respondents, coordination would establish a level playing field for all trading venues when consistently applied and enforced by regulators.

\footnotetext{
${ }^{17}$ As it is not expedient for the purpose of this section, no distinction is applied between cash and derivatives markets.

${ }^{18}$ Respondents were asked to only select pro arguments if they are in favor of coordinating circuit breakers or undecided regarding this issue. Likewise, only respondents who are against coordination or undecided were asked to select contra arguments.
} 
One of the undecided respondents additionally noted that coordination may be unnecessary under standard market conditions. However, in case of extreme volatility, cooperation between trading venues can contribute to market stabilization. One exchange that already coordinates circuit breakers domestically pointed out that coordination is necessary and has proven to work well in the past. Another respondent indicated that coordinated circuit breakers across trading venues are beneficial and in the interest of market operators and market participants as traders would otherwise switch to other trading venues which might increase volatility even further (these answers are reflected in the category "Others" in Figure 24).

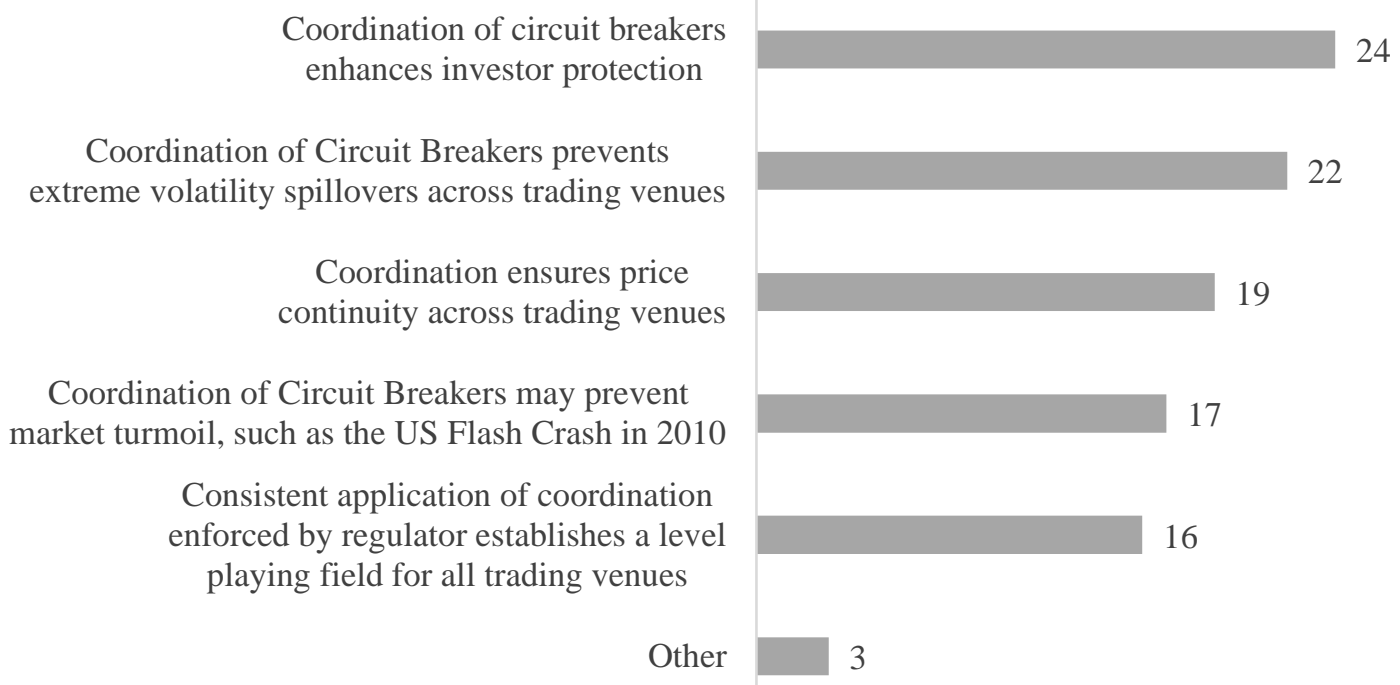

Figure 24: Supporting arguments for coordination of circuit breakers across trading venues (20 supporters of coordination and four undecided respondents are reflected in this figure).

Of the nine exchanges that are against a coordination of circuit breakers or that are undecided, eight respondents indicated that order book imbalances should be solved locally at the respective market (Figure 25). Five respondents claim that technical issues may arise in the coordination and timing process, which makes coordination difficult and less effective. Another four respondents note that coordination is already achieved implicitly due to traders' behavior. Additional costs caused by set up and maintenance of necessary systems are cited by three exchanges. Only one venue raised the concern that there is a lack of transparency on which trading venues certain instruments are traded.

Two of the respondents strongly disagree with the concept of coordinating circuit breakers across trading venues and urge additional arguments. They argue that in order to be most ef- 
fective, parameters for circuit breakers need to be directly tailored to the market where an instrument is traded and trading venue operators need to be able to adjust these parameters in response to movements in an instrument's price and market activity. Therefore, each trading venue should be allowed to implement the most suitable type of circuit breaker for their markets. Coordination, however, would equalize circuit breakers and respective parameters across trading venues. Additionally, different circuit breakers were developed and continuously improved due to the competition between markets. Consequently, these mechanisms are part of the service offering and value proposition of each trading venue. When coordinated, the competitive element of developing and improving circuit breakers would be eliminated. One trading venue points out that coordination is not necessary since it is the only venue in the respective country on which instruments are traded. Consequently, there is low correlation with other venues. An undecided respondent suggested coordination might not be essential as most venues have some kind of circuit breakers (these answers are reflected in the category "Others" in Figure 25).

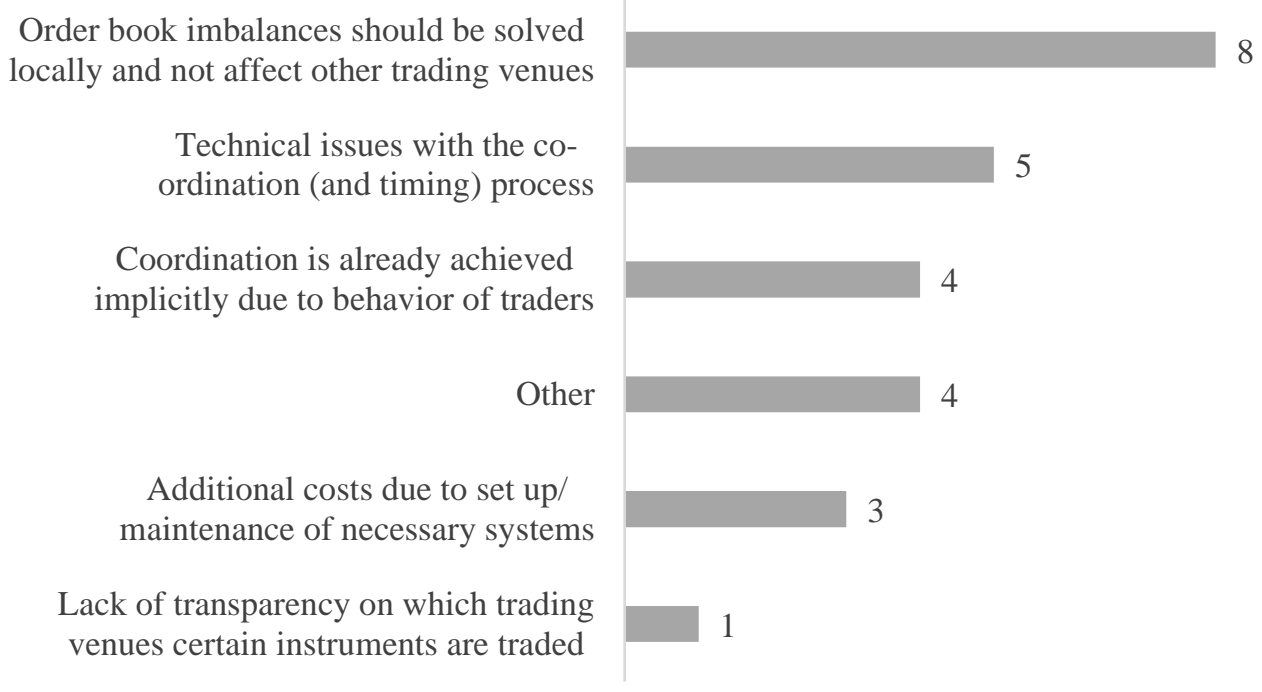

Figure 25: Arguments against coordinating circuit breakers across trading venues (five opponents of coordination and four undecided respondents are reflected in this figure).

Currently, twelve of the responding exchanges coordinate circuit breakers with other trading venues. This accounts for $32 \%$ of the responding exchanges that employ circuit breakers. Eleven exchanges provided information on which components of a triggered circuit breaker are coordinated (Figure 26). Typically, trading venues transmit the circuit breaker event itself, and the exact start and end time of the circuit breaker. When extensions are provided in the mechanism (at eight out of nine exchanges), these are coordinated as well. The coordination of 
circuit breakers was initiated in six cases by the regulator and in another six cases by the exchange itself.

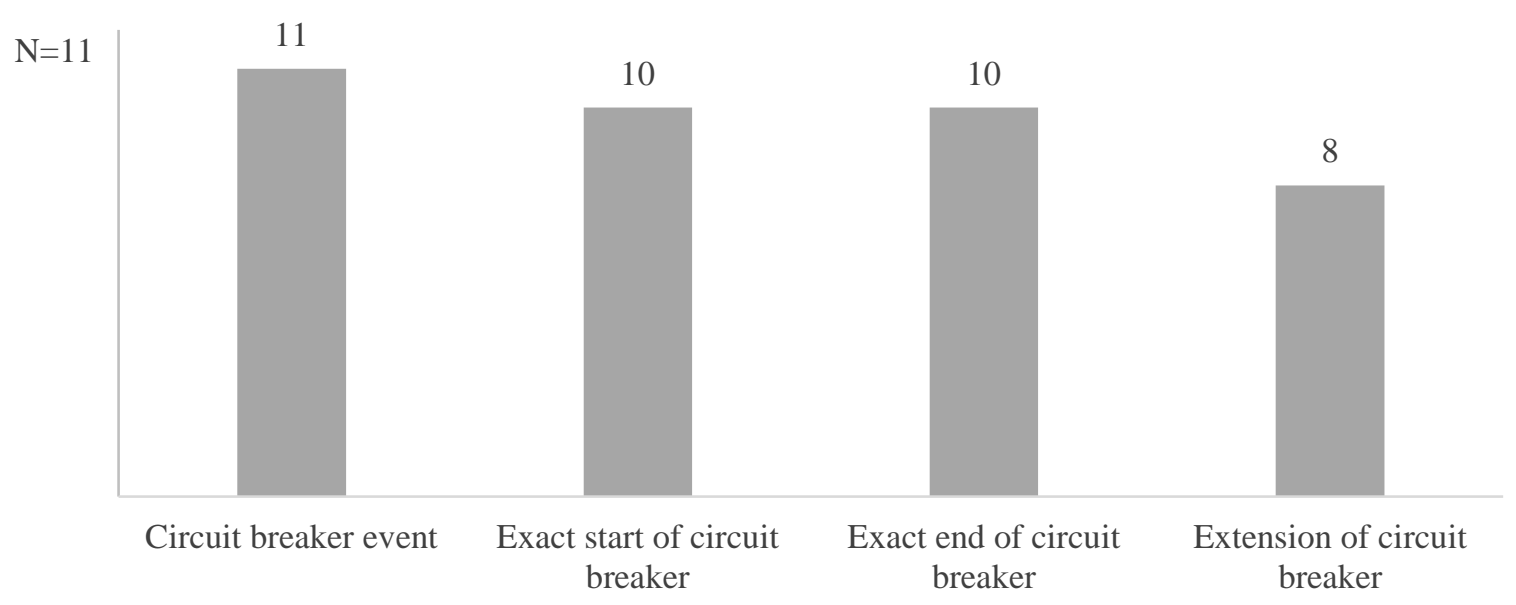

Figure 26: Shared components of coordinated circuit breakers (eleven of twelve coordinating exchanges provided an answer).

\section{$9 \quad$ Summary and Key Takeaways}

This survey among international trading venues provides valuable insights into circuit breaker practices and contributes to an enhancement of knowledge on current market infrastructure. The systematic information collection supports market operators and regulators in the configuration and further enhancement of circuit breakers. It also establishes a common ground for discussions on the issue of coordinating circuit breakers in times of highly fragmented order flow. In addition, the results of this study intend to communicate the efforts of trading venues and regulators in improving market integrity to the public.

To the best of our knowledge, this comprehensive compilation of information about implemented volatility safeguard mechanisms is the first since 2008, when the WFE conducted a similar survey among its member exchanges. At that time $60 \%$ of the responding 40 exchanges employed circuit breakers. Within this survey, we received responses from 44 trading venues that altogether operate 39 cash and 23 derivatives markets ${ }^{19} .86 \%$ of all trading venues indicated that they currently apply such mechanisms. Two cash markets and four derivatives markets that do not employ circuit breaker mechanisms said they have concrete plans for an implementation. There are 24 exchanges that participated both in the 2008 and the 2016 survey. Among those, the number of exchanges that have circuit breakers in place increased from 16

\footnotetext{
${ }^{19}$ However, only 20 derivatives markets are included in this survey as we did not receive the responses for the derivatives markets of three exchanges that operate both cash and derivatives markets.
} 
in 2008 to 22 in 2016 (see Appendix D). It can thus be concluded that the active usage of circuit breakers continues to progress.

The study identified 56 distinct circuit breaker mechanisms, 47 of which are implemented on cash and nine on derivatives markets. In addition, six exchanges extend circuit breakers that are triggered on their respective cash market to their derivatives market. The results of the survey show that the most common types of circuit breakers are market-wide trading halts and volatility interruptions. The former mechanism was implemented in 20 markets (17 on cash and three on derivatives markets), the latter in 19 markets (17 cash and two derivatives markets). Unsurprisingly, all index triggered mechanisms lead to a market-wide trading halt. Volatility interruptions are especially common in Europe whereas market-wide suspensions can be observed globally. A smaller proportion of markets indicated that their most relevant stock triggered circuit breaker is an order rejection mechanism (eight cash and one derivatives markets) or a single-instrument trading halt (four cash and three derivatives markets).

The majority of circuit breakers do not differentiate between upward or downward market movements. On the cash market segment, only 15 of 47 mechanisms react solely to downward market movements. Similarly, 13 of 15 circuit breakers on the derivatives markets are triggered in both directions. Only in two cases of internal coordination between cash and derivatives markets, the respective trading halt on both market segments is only triggered in downward market movements.

Differences between cash and derivatives market circuit breakers were also observed as regards the determination of thresholds. Whereas only 4\% (two of 47) of the cash market mechanisms make use of computational models, $56 \%$ of distinct (five of nine) derivatives market circuit breaker thresholds are determined that way. Predetermined price ranges, on the other hand, are used for $96 \%$ of the cash market and for $44 \%$ of the derivatives market circuit breakers. Predetermined price ranges are either static or dynamic with the former type being set wider than the latter. It is noticeable that only volatility interruption mechanisms and three order rejection mechanisms apply dynamic price ranges (in most cases in combination with static ranges). The other circuit breakers rely on static price ranges, which typically refer to the previous day's closing or last auction prices. The vast majority (93\%) of responding exchanges publish all information regarding the threshold determination process. However, three exchanges only make general information transparent but do not disclose specific parameters such as the width of price ranges. 
In case of a circuit breaker event, market-wide trading halts interrupt the normal trading process longer than volatility interruptions or single-instrument trading halts. Eight exchanges have defined levels that would, once triggered, suspend trading on the whole market for the rest of the day. However, these market-wide events occur rarely.

Apart from the triggering process and the consequences of activated mechanisms, the survey also looked at the issue of coordinating circuit breakers across trading venues. In times of highly fragmented markets in several jurisdictions, it may be necessary to coordinate circuit breakers in order to ensure their functionality. Despite the majority of responding exchanges (20/29) favoring coordination across trading venues, only twelve exchanges (32\% of responding exchanges) currently align their circuit breakers with another market. However, coordination is only arranged between domestic exchanges or between trading venues that are historically or geographically connected to each other. Most supporters of coordination agree that it would enhance investor protection and prevent extreme volatility spillovers across trading venues. Opponents, on the other hand, note that order book imbalances should be solved locally and that there are technical issues with the coordination and timing process of circuit breakers. Circuit breakers are mostly within the exchanges' responsibility or the responsibility of the respective provision is shared with the national regulator. Periodic revision processes are defined at $44 \%$ of the responding trading venues. Such revisions are frequently followed by modifications of certain parameters such as the width of price ranges or duration. Drastic changes of circuit breaker provisions are rare. Only one responding exchange indicated that its circuit breaker provision was amended in the context of the recent financial crisis. The respective exchange narrowed its price ranges due to the increased volatility at that time.

In summary, we can conclude that the application of circuit breakers has become established and very common among global trading venues. Trading venues employ such mechanisms on their cash as well as on their derivatives markets. Our study suggests that there is support for greater coordination of circuit breakers across venues. How to give effect to this would be a worthwhile area of investigation both for academics and practitioners. 


\section{References}

Abad, D., \& Pascual, R. (2010). Switching to a Temporary Call Auction in Times of High Uncertainty. Journal of Financial Research, 33(1), 45-75.

Abad, D., \& Pascual, R. (2013). Holding Back Volatility - Circuit Breakers, Price Limits, and Trading Halts. In H. Baker, \& H. Kiymaz, Market Microstructure in Emerging and Developed Markets: Price Discovery, Information Flows, and Transaction Costs (pp. 303-324). John Wiley \& Sons, Inc.

Brady, N. (1988). Report of the Presidential Task Force on Market Mechanisms. Washington, DC: Government Printing Office, Department of the Treasury.

Brugler, J., \& Linton, O. B. (2016). The Cross-Sectional Spillovers of Single Stock Circuit Breakers. Working Paper.

Christie, W., Corwin, S. A., \& Harris, J. (2002). Nasdaq Trading Halts: The Impact of Market Mechanisms on Prices, Trading Activity, and Execution Costs. The Journal of Finance, 57(3), 1443-1478.

Corwin, S. A, \& Lipson, M. L. (2000). Order Flow and Liquidity around NYSE Trading Halts. The Journal of Finance, 55(4), 1771-1805.

Fama, E. (1989). Perspectives on October 1987, or, What Did We Learn from the Crash? In R. J. Barro, \& R. W. Kamphuis Jr., Black Monday and the Future of Financial Markets (pp. 71-82). Homewood, IL: Irwin.

Gomber, P., Haferkorn, M., Lutat, M., \& Zimmermann, K. (2013). The Effect of Single-Stock Circuit Breakers on the Quality of Fragmented Markets. In F. A. Rabhi \& P. Gomber, Enterprise Applications and Services in the Finance Industry (pp. 71-87). Springer Berlin Heidelberg.

Kim, Y. H., Yagüe, J., \& Yang, J. J. (2008). Relative Performance of Trading Halts and Price Limits: Evidence from the Spanish Stock Exchange. International Review of Economics and Finance, 17(2), 197-215.

Lauterbach, B., \& Ben-Zion, U. (1993). Stock Market Crashes and the Performance of Circuit Breakers: Empirical Evidence. The Journal of Finance, 48(5), 1909-1925.

Ma, C., Rao, R., \& Sears, R. (1989). Volatility, Price Resolution, and the Effectiveness of Price Limits. Journal of Financial Services Research, 22(2), 165-199. 
Madhavan, A. (1992). Trading Mechanisms in Securities Markets. The Journal of Finance, 47(2), 607-641.

Moser, J. (1990). Circuit Breakers. Economic Perspectives, 2-13.

Subrahmanyam, A. (1994). Circuit Breakers and Market Volatility: A Theoretical Perspective. The Journal of Finance, 49(1), 237-254.

WFE. (2008). Questionnaire on Circuit Breakers for Q4 2008. World Federation of Exchanges.

WFE. (2015). Monthly Reports, December 2015. Retrieved June 1, 2016, from World Federation of Exchanges - Statistics: http://www.world-exchanges.org/home/index.php /statistics/monthly-reports 


\section{Appendix}

\section{A. Participating Venues}

\begin{tabular}{|c|c|c|c|c|}
\hline Region & Cash market only & $\begin{array}{l}\text { Derivatives } \\
\text { market only }\end{array}$ & $\begin{array}{c}\text { Both market } \\
\text { segments operated }\end{array}$ & Total \\
\hline Americas & $\begin{array}{l}\text { Bolsa de Comercio de Santiago } \\
\text { Bolsa de Valores de Lima }\end{array}$ & $\begin{array}{l}\text { CBOE } \\
\text { CME } \\
\text { International } \\
\text { Securities Ex- } \\
\text { change }\end{array}$ & $\begin{array}{l}\text { BM\&FBOVESPA } \\
\text { Bolsa Mexicana de Valores* } \\
\text { Bolsa de Valores de Colom- } \\
\text { bia } \\
\text { Intercontinental Exchange } \\
\text { (NYSE) } \\
\text { Nasdaq U.S. }\end{array}$ & 10 \\
\hline $\begin{array}{l}\text { Asia- } \\
\text { Pacific }\end{array}$ & $\begin{array}{l}\text { Australian Securities Exchange } \\
\text { Bursa Malaysia } \\
\text { Colombo Stock Exchange } \\
\text { Hochiminh Stock Exchange } \\
\text { Philippine Stock Exchange } \\
\text { Shenzhen Stock Exchange } \\
\text { Taipei Exchange }\end{array}$ & $\begin{array}{l}\text { TAIFEX } \\
\text { Shanghai Fu- } \\
\text { tures Exchange }\end{array}$ & $\begin{array}{l}\text { BSE India } \\
\text { Hong Kong Exchanges and } \\
\text { Clearing } \\
\text { Japan Exchange Group } \\
\text { Korea Exchange* } \\
\text { NSE India } \\
\text { Stock Exchange of Thailand }\end{array}$ & 15 \\
\hline $\begin{array}{c}\text { Europe, } \\
\text { Africa, } \\
\text { Middle } \\
\text { East }\end{array}$ & $\begin{array}{l}\text { Amman Stock Exchange } \\
\text { Aquis*** } \\
\text { Cyprus Stock Exchange } \\
\text { Dubai Financial Market } \\
\text { Egyptian Exchange } \\
\text { Irish Stock Exchange } \\
\text { Kazakhstan Stock Exchange } \\
\text { Luxembourg Stock Exchange } \\
\text { Nasdaq Nordic** } \\
\text { Saudi Stock Exchange (Tadawul) } \\
\text { SIX Swiss Exchange } \\
\text { Stock Exchange of Mauritius }\end{array}$ & & $\begin{array}{l}\text { Athens Stock Exchange } \\
\text { BME Spanish Exchanges* } \\
\text { Deutsche Börse } \\
\text { Johannesburg Stock Ex- } \\
\text { change } \\
\text { Moscow Exchange } \\
\text { Tel-Aviv Stock Exchange } \\
\text { Warsaw Stock Exchange*** }\end{array}$ & 19 \\
\hline Total & 21 & 5 & 18 & 44 \\
\hline
\end{tabular}

Table 9: Participating trading venues classified by region and operated market segments (for regional allocation monthly WFE reports were used (WFE, 2015)). * The respondent only answered for the cash market. For the remainder of the survey analysis, only the cash market is covered. ** Answers for Nasdaq Nordic were provided by Nasdaq Iceland. *** Not WFE member. 


\section{B. Venues with Circuit Breakers}

\begin{tabular}{|c|c|}
\hline \multicolumn{2}{|c|}{ Trading venues that apply circuit breakers } \\
\hline Amman Stock Exchange & Intercontinental Exchange (NYSE) \\
\hline Aquis* & Irish Stock Exchange \\
\hline Athens Stock Exchange & Japan Exchange \\
\hline Australian Securities Exchange & Johannesburg Stock Exchange \\
\hline BM\&FBOVESPA & Kazakhstan Stock Exchange \\
\hline BME Spanish Exchanges & Korea Exchange \\
\hline Bolsa de Comercio de Santiago & Luxembourg Stock Exchange \\
\hline Bolsa de Valores de Colombia & Moscow Exchange \\
\hline Bolsa de Valores de Lima & Nasdaq U.S. \\
\hline Bolsa Mexicana de Valores & Nasdaq Nordic \\
\hline BSE India & NSE India \\
\hline Bursa Malaysia & Philippine Stock Exchange \\
\hline CBOE & Saudi Stock Exchange (Tadawul) \\
\hline CME & SIX Swiss Exchange \\
\hline Colombo Stock Exchange & Stock Exchange of Mauritius \\
\hline Cyprus Stock Exchange & Stock Exchange of Thailand \\
\hline Deutsche Börse & TAIFEX \\
\hline Dubai Financial Market & Tel-Aviv Stock Exchange \\
\hline Egyptian Exchange & Warsaw Stock Exchange* \\
\hline
\end{tabular}

Table 10: List of responding trading venues that currently apply circuit breakers. * Not WFE member.

\section{Venues without Circuit Breakers}

\begin{tabular}{|c|c|}
\hline \multicolumn{2}{|c|}{ Trading venues that do not apply circuit breakers } \\
\hline Hochiminh Stock Exchange & International Securities Exchange ${ }^{20}$ \\
\hline Hong Kong Exchanges and Clearing ${ }^{21}$ & Shanghai Futures Exchange \\
\hline Taipei Exchange & Shenzhen Stock Exchange \\
\hline
\end{tabular}

Table 11: List of responding trading venues that currently do not apply circuit breakers.

\footnotetext{
${ }^{20}$ International Securities Exchange does not use own circuit breakers on its derivatives market. However, it reacts to and abides by the circuit breakers implemented by the underlying cash markets and related futures markets.

${ }^{21}$ Hong Kong Exchanges and Clearing indicated in the survey that they plan to implement a circuit breaker in 2016. On August 22, 2016, the exchange introduced the Volatility Control Mechanism, which is a circuit breaker applied at the individual instrument level.
} 


\section{Participating Venues in the 2008 and 2016 WFE Surveys on Circuit Breakers}

\begin{tabular}{|c|c|c|}
\hline Exchanges & CB in 2008 & CB in 2016 \\
\hline Athens Exchange & $\mathrm{X}$ & $\mathrm{X}$ \\
\hline BME & $\mathrm{X}$ & $\mathrm{X}$ \\
\hline Bolsa de Valores de Colombia & $\mathrm{X}$ & $\mathrm{X}$ \\
\hline Bolsa Mexicana de Valores & $\mathrm{X}$ & $\mathrm{X}$ \\
\hline Bourse de Luxembourg & $X$ & $\mathrm{X}$ \\
\hline CBOE & $X$ & $\mathrm{X}$ \\
\hline Deutsche Börse AG & $\mathrm{X}$ & $\mathrm{X}$ \\
\hline Irish Stock Exchange & $X$ & $\mathrm{X}$ \\
\hline Korea Exchange & $X$ & $\mathrm{X}$ \\
\hline Nasdaq Nordic & $\mathrm{X}$ & $\mathrm{X}$ \\
\hline Nasdaq U.S. & $\mathrm{X}$ & $\mathrm{X}$ \\
\hline NSE India & $\mathrm{X}$ & $\mathrm{X}$ \\
\hline SIX Swiss Exchange & $\mathrm{X}$ & $\mathrm{X}$ \\
\hline Stock Exchange of Thailand & $X$ & $X$ \\
\hline Tel Aviv Stock Exchange & $\mathrm{X}$ & $\mathrm{X}$ \\
\hline Tokyo Stock Exchange Group, Inc. & $\mathrm{X}$ & $\mathrm{X}$ \\
\hline Amman Stock Exchange & & $\mathrm{X}$ \\
\hline Australian Securities Exchange & & $\mathrm{X}$ \\
\hline Bolsa de Comercio de Santiago & & $\mathrm{X}$ \\
\hline Colombo Stock Exchange & & $\mathrm{X}$ \\
\hline Cyprus Stock Exchange & & $\mathrm{X}$ \\
\hline Intercontinental Exchange (NYSE) & & $\mathrm{X}$ \\
\hline \multicolumn{3}{|l|}{ Hong Kong Exchanges and Clearing } \\
\hline \multicolumn{3}{|l|}{ International Securities Exchange } \\
\hline Total & 16 & 22 \\
\hline
\end{tabular}

Table 12: List of venues that participated both in the 2008 and 2016 WFE Survey on circuit breakers. 


\section{E. Market Models of the Survey Participants}

Of the 38 cash markets that provided information about their market model, 31 employ orderdriven and seven hybrid market models ${ }^{22}$. None of the responding cash markets operates a purely quote-driven market model (Figure 27).

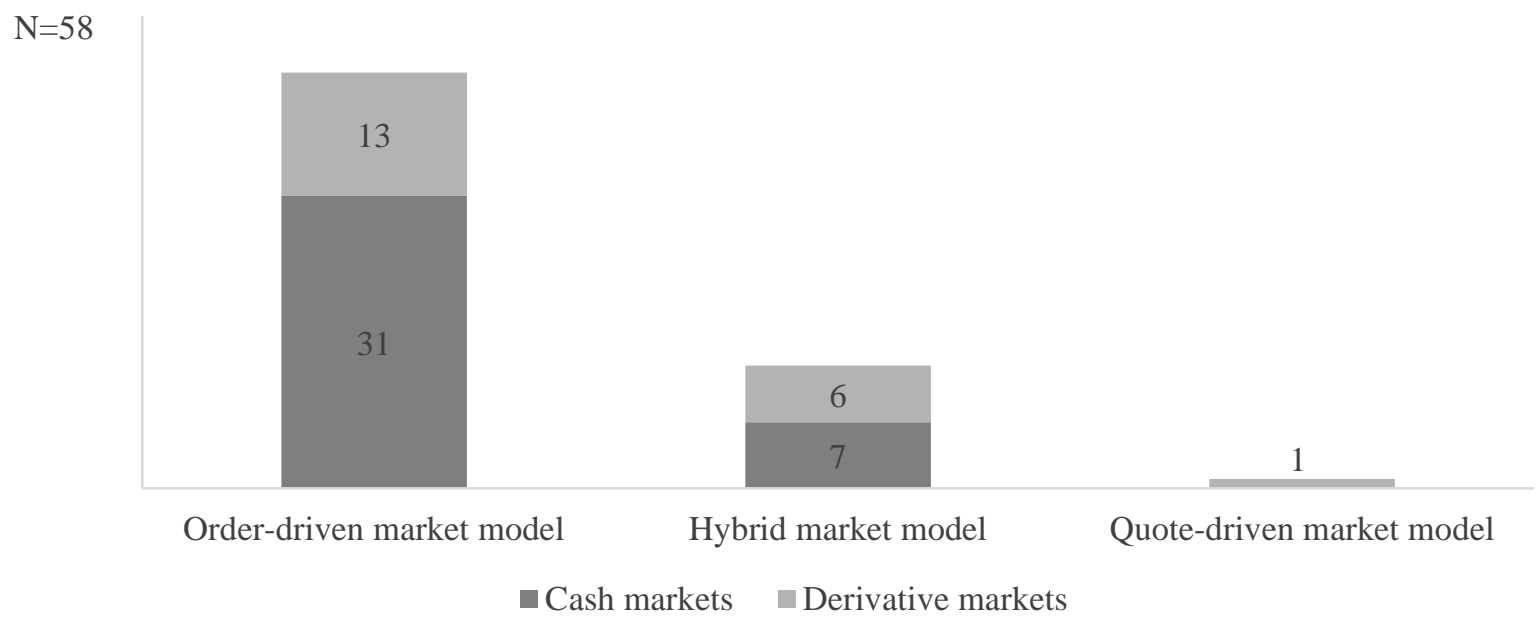

Figure 27: Used market models on cash and derivatives markets.

Of the 20 surveyed derivatives markets, 13 utilize order-driven models and six rely on hybrid models. One derivatives market uses a quote-driven model.

A common component of the three market models is the concept of call auctions. Within the group of 39 answering cash markets, 34 (87\%) utilize call auctions. The majority (25) of these markets indicated that auctions take place at the beginning and at the end of the trading day ${ }^{23}$. Five cash markets only apply auctions at the opening, whereas one venue uses auctions only for initial public offerings and share repurchases on the request of the issuing company (three venues did not state the timing of their auctions). Scheduled auctions are implemented at twelve out of $20(60 \%)$ responding derivatives markets. Six of these markets apply both opening and closing auctions, whereas four respondents indicated that auctions are only scheduled for the opening (two venues did not state the timing of their auctions).

\footnotetext{
${ }^{22}$ For the purpose of the survey, a hybrid market model is defined as a mixture of order-driven and quote-driven market models, depending on the liquidity of different securities. One venue did not answer this question.

${ }^{23}$ As the only respondent, Deutsche Börse additionally runs an intraday auction.
} 


\section{F. Historical Development of Circuit Breaker Implementations by Region}

Development of circuit breaker implementations in the Americas (Figure 28):

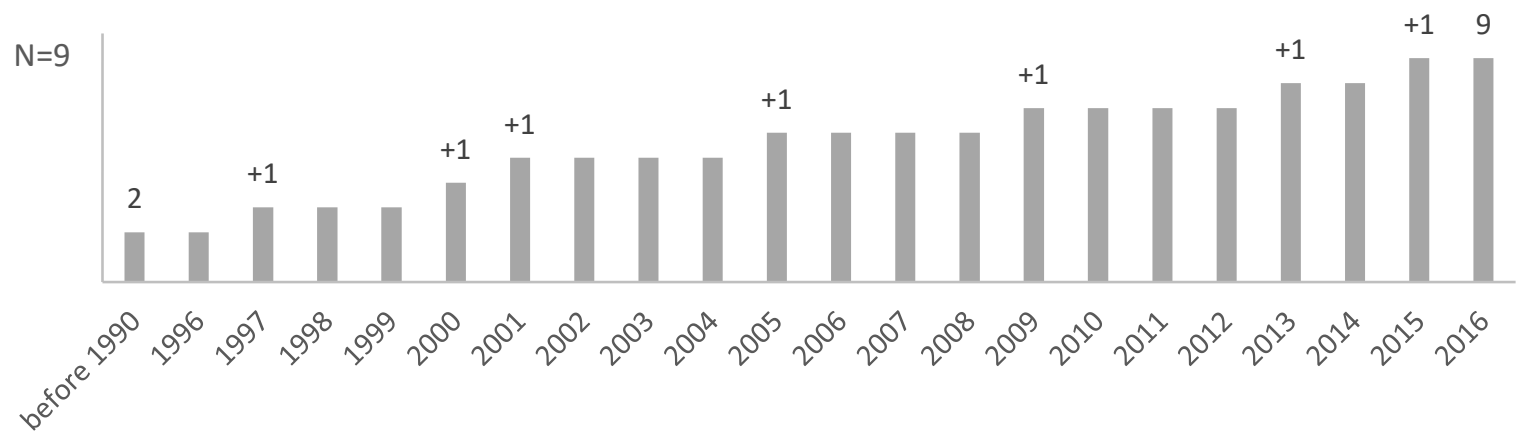

Figure 28: Time sequence of circuit breaker implementation across the nine trading venues in the Americas that use circuit breakers.

Development of circuit breaker implementations in Asia-Pacific (Figure 29):

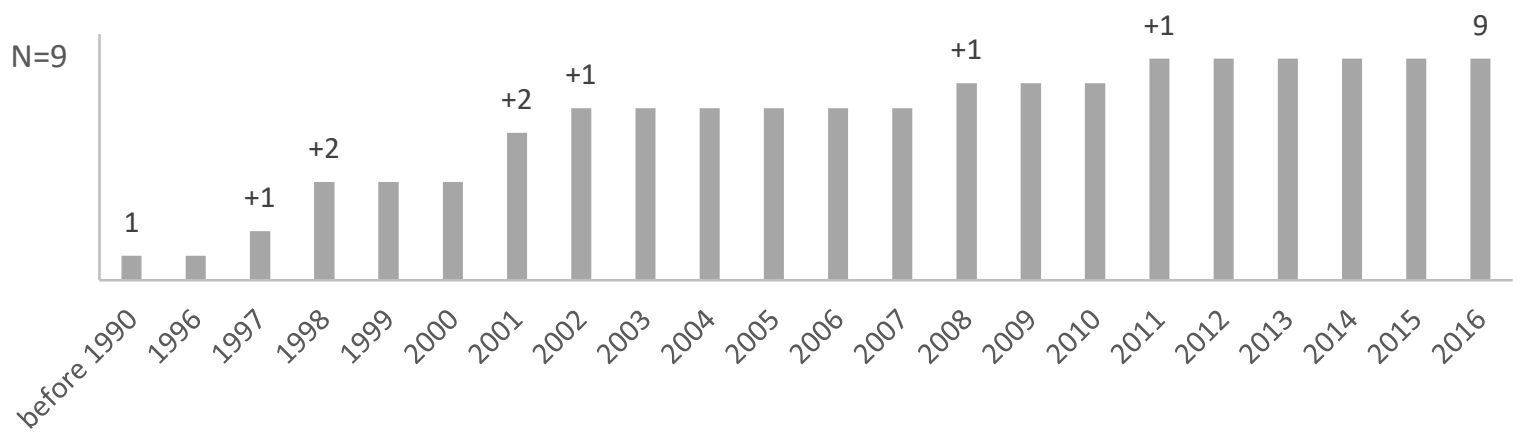

Figure 29: Time sequence of circuit breaker implementation across nine trading venues in the Asia-Pacific region (one of the ten exchanges in Asia-Pacific that use circuit breakers did not provide the implementation date).

Development of circuit breaker implementations in Europe, Africa, and the Middle East (Figure 30):

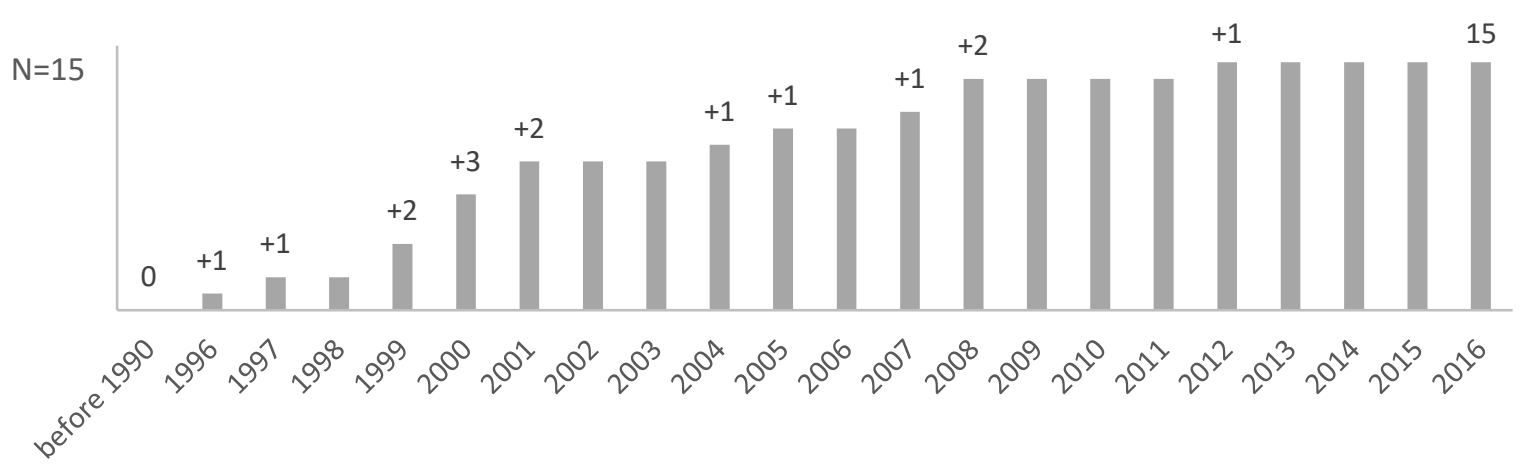

Figure 30: Time sequence of circuit breaker implementation across 15 trading venues (four of the 19 exchanges in the Europe, Africa, and the Middle East did not provide the implementation date of their circuit breaker). 


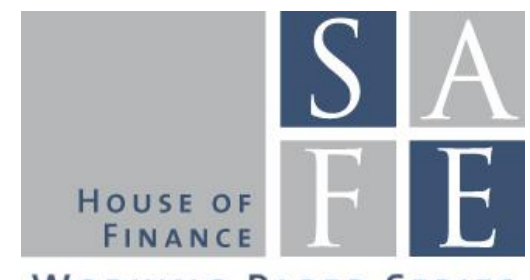

Working PAPER SERIES

\section{Recent Issues}

No. 196 Benjamin Clapham, Peter Gomber, Sven Panz

No. 195 Benjamin Clapham, Peter Gomber, Martin Haferkorn, Sven Panz

No. 194 Baptiste Massenot

No. 193 Mario Bellia, Roberto Panzica, Loriana Pelizzon, Tuomas Peltonen

No. 192 Vincenzo Pezone

No. 191 Julia Hirsch, Uwe Walz

No. 190 Vanya Horneff, Raimond Maurer, Olivia S. Mitchell

No. 189 Carlo Wix

No. 188 Michael Donadelli, Patrick Grüning, Marcus Jüppner, Renatas Kizys

No. 187 Baptiste Massenot, Yuri Pettinicchi

No. 186 Nicole Branger, Paulo Rodrigues, Christian Schlag

No. 185 Patrick Grüning

No. 184 Tobias Tröger
Coordination of Circuit Breakers? Volume

Migration and Volatility Spillover in

Fragmented Markets

Managing Excess Volatility: Design and Effectiveness of Circuit Breakers

A Business Cycle Model with Neuroeconomic Foundations

The Demand for Central Clearing: To Clear or Not to Clear, That is the Question

The Real Effects of Judicial Enforcement: Evidence from Italy

Financial constraints, newly founded firms and the financial crisis

How Persistent Low Expected Returns Alter Optimal Life Cycle Saving, Investment, and Retirement Behavior

The Long-Run Real Effects of Banking Crises: Firm-Level Investment Dynamics and the Role of Wage Rigidity

Global Temperature, R\&D Expenditure, and Growth

Can Firms see into the Future?

Survey evidence from Germany

Level and Slope of Volatility Smiles in LongRun Risk Models

Heterogeneity in the Internationalization of R\&D: Implications for Anomalies in Finance and Macroeconomics

Remarks on the German Regulation of Crowdfunding 